\title{
Modality effects and the structure of short-term verbal memory
}

\author{
CATHERINE G. PENNEY \\ Memorial University of Newfoundland, St. John's, Newfoundland, Canada
}

\begin{abstract}
The effects of auditory and visual presentation upon short-term retention of verbal stimuli are reviewed, and a model of the structure of short-term memory is presented. The main assumption of the model is that verbal information presented to the auditory and visual modalities is processed in separate streams that have different properties and capabilities. Auditory items are automatically encoded in both the A (acoustic) code, which, in the absence of subsequent input, can be maintained for some time without deliberate allocation of attention, and a P (phonological) code. Visual items are retained in both the $P$ code and a visual code. Within the auditory stream, successive items are strongly associated; in contrast, in the visual modality, it is simultaneously presented items that are strongly associated. These assumptions about the structure of shortterm verbal memory are shown to account for many of the observed effects of presentation modality.
\end{abstract}

Penney (1975) reviewed the literature on the effects of presentation modality on short-term retention of verbal material and concluded that there were separate stores for auditorily and visually presented information. To emphasize the idea that active processing underlies retention in short-term memory, and to discourage the conceptualization of short-term memory as a warehouse of decaying information, Penney (1980) introduced the term separate processing streams to replace the notion of separate memory stores. Since publication of the review paper, additional work on modality effects has supported the hypothesis of modality separation in the processing of verbal material in short-term memory (the separate-streams hypothesis), and new findings have elucidated the nature of the separate processing streams. The present paper is a review of the literature on modality effects and related phenomena, with the goal of presenting an integrated account in terms of the different properties and capabilities of the separate processing streams. These processing streams are seen to reflect the inherent structure of short-term verbal memory, and not to represent strategic processes.

In 1975, the term modality effect referred to the finding that, in short-term memory tasks, auditory presentation almost always resulted in higher recall than did visual presentation. This modality effect was found for the recency part of the serial position curve in immediate free recall and in serial recall, and the auditory superiority was also found in the Peterson distractor task, provided that

I would like to thank Donald Broadbent, Robert Crowder, Susan Manning, Bennet Murdock, James Nairne, Lars-Göran Nilsson, Charles Thompson, and Michael Watkins for their helpful comments on earlier drafts of the paper. Reprint requests may be addressed to the author, Psychology Department, Memorial University of Newfoundland, St. John's, Newfoundland A1B 3X9, Canada. the distraction did not require a long period of vocalization. Overt vocalization of a visually presented list by the subject produced much the same effect as did auditory presentation on the recency part of the serial position curve, but subject vocalization tended to reduce recall in the nonrecency part of the serial position curve. In spite of the large and robust effects of presentation modality found in short-term memory tasks, there was no evidence of any permanent effects on learning, and modality effects in long-term memory tasks were conspicuously absent.

One interpretation of the modality effect was that it reflected an auditory sensory store (called the precategorical acoustic store, or PAS, by Crowder \& Morton, 1969). The PAS maintained a sensory trace of the last one or two items for a few seconds, and this sensory trace supplemented the information maintained through rehearsal in short-term memory. The interpretation of the modality effect in terms of an auditory sensory store accounted for many effects known at the time, and it certainly stimulated new work. However, it had one unintended but unfortunate effect: The PAS model relegated modality effects to a peripheral place in memory. A sensory store contains traces that either fade rapidly or are displaced by subsequent information, and information in the sensory store does not contribute to the memory trace that is formed in permanent memory. It is obvious that the study of this ephemeral trace would not advance our understanding of the central issues in human learning and memory. In contrast to this view of modality effects as being inconsequential, I want to argue that modality effects reflect the inherent structure of short-term memory, and that no theory of human memory will be adequate if it does not provide a complete account of these phenomena.

For pragmatic reasons, the present review is focused exclusively on the processing and retention of verbal 
material. With verbal material, it is possible to vary input modality and keep the informational content of the memory material the same. But the most important reason for restricting consideration to verbal material at this stage is that it provides an appropriate anchor for further theoretical development. A theoretical description of verbal processing mechanisms provides a conceptual link between the mechanisms for processing nonverbal material in the auditory and visual modes. Mechanisms underlying short-term retention of nonspeech sounds and pictures may have so little in common that a comparison between the two is meaningless. But one can compare retention of auditorily and visually presented words under parallel presentation conditions. The differences between the two modalities that become apparent when materials and procedures are comparable provide an empirical basis for a theory about the structure of memory. One can then make comparisons within each modality between verbal and nonverbal material and thereby extend the theory.

The human memory system is highly flexible and adaptive. Information presented in any modality can be recoded into almost any other format. For example, a person hearing a word can visualize the object represented by the word, can visualize the appearance of the typed word, can silently articulate the word or spell it out, and can imagine writing the word or forming it in sign language. It is necessary to distinguish a memory trace or code established after sensory and perceptual processing from a trace resulting from the subject's recoding of the item. I will argue that the short-term memory trace laid down when the subject silently articulates a visually presented item or imagines the sound of that item does not contain the same information as the trace resulting from auditory presentation of the item. The term sensory-based trace or code will be used to refer to the information stored as a result of sensory and perceptual processing, and the term internally generated will refer to information stored as a result of the subject's transformation or enrichment of a sensory-based trace.

In particular, the code generated by silent articulation of visually presented items is called the $P$ (phonological) code and is internally generated. The P code is similar to Baddeley's $(1983,1986)$ phonological code, which is produced by the activity of the articulatory loop, and results from the addition to the trace of knowledge about words and phonemes, including articulatory information. The sensory-based code created as a result of auditory presentation will be called the A (acoustic) code. Whereas the $\mathrm{P}$ code is common to both auditorily and visually presented stimuli, the A code is produced only for stimuli that are heard. The A code is hypothesized to be rich and very durable relative to a visual sensory code. It is the persistence of the A code that boosts recall of recent auditory items relative to visual items in short-term memory tasks and thereby produces the modality effect.

\section{A Model for Short-Term Memory}

To account for the various modality effects, I will propose a model of the structure of short-term memory. By means of a small number of hypotheses about the properties of the memory system, most of the observed modality effects can be accounted for. The list of the hypothesized properties can later be expanded, if necessary, to account for new modality effects as they are reported. Furthermore, modality effects in long-term memory can probably be accommodated within the framework of the model, as will become apparent.

The traditional view of memory claims that perceptual processing extracts the meaning of a stimulus, and that this meaning forms the core of the memory trace. In this view, information about sensory properties of the stimulus is stored as tags or features or attributes that are somehow appended to the trace. The memory trace is a highly abstracted-some would say propositional-representation. Contrasted to the traditional view is the proceduralist view of Paul Kolers, according to which knowledge and its representation in memory are not independent of the way in which the knowledge was acquired.

On a procedural account, knowledge acquired through reading or listening depends on cognitive skills of the perceiver. Application of these skills is often directed at features of the message that most theorists consider superficial-cadence or pitch of a voice, typography, spacing, or orientation of a written text, and the like. Thus, according to the procedural view, and in contrast with some other views, these features should play a prominent role in forming the representation of the message in memory. (Kolers \& Roediger, 1984, p. 430)

The proceduralist view presented in the quotation above forms the basis of the model. The processing of an item in short-term memory develops from and is continuous with perceptual processing. There is no distinct boundary between the two. The perceptual processing provides the basis of the memory trace; meaning is added later. In other words, the sensory aspects of the memory trace are primary and the semantic aspects secondary-not the reverse, as is commonly held. The traditional view of memory deemphasizes the role of sensory information and assigns modality effects in short-term memory a peripheral function. The traditional view suggests that modality effects in long-term memory will be insignificant, and this is probably the reason why few investigators have examined them. In contrast, the proceduralist account implies that modality differences that characterize short-term memory processing should be reflected in the long-term memory trace. Not only should there be observable modality effects in long-term memory tasks, these effects will reflect the different properties of the auditory and visual perceptual and memory systems.

The main hypothesis of the model is that the processing of auditorily and visually presented verbal items is carried out separately in short-term memory (the separate-streams hypothesis). The processing mechanisms are specific to either the auditory or the visual stream, and the two streams have different properties and capabilities and represent information in different ways. In the auditory stream, the items are represented automatically in the A and $P$ codes, and a subject cannot voluntarily prevent entry 
of an auditory item into short-term memory. The A code contains sensory information that, in the absence of interference, persists in useful form in short-term memory for up to a minute. It is the availability of this information that underlies the often noted superiority of auditory presentation, and it is the displacement of this information that underlies the auditory suffix effect. Within the auditory stream, items are organized most strongly along the temporal dimension, an organization that is manifested in the strong associations between successive items. The sequential associations may also contribute to the superior recall of auditory items in short-term memory tasks that require retention of order information. In the visual modality, items are normally represented in the $\mathrm{P}$ code. However, generation of the $P$ code is not automatic and can be disrupted, for example by simultaneous speech. There is also a visually based code, which Baddeley $(1983,1986)$ called the visuospatial scratch pad, and which is manifested when use of the P code is disrupted. In contrast to the temporal organization in the auditory mode, whereby successive items are strongly associated, it appears that in the visual mode, items presented simultaneously are more strongly associated.

\section{Outline of the Paper}

The present article is divided into three main parts. The first section contains a review of several different lines of evidence that support the hypothesis of separate processing systems for auditorily and visually presented material. In the second section, the Crowder and Morton PAS model and the translation hypothesis will be discussed and shown not to provide an adequate account of the many different modality effects. In the third section, some of the evidence pertaining to the hypothesized properties of the auditory and visual processing subsystems will be briefly summarized.

\section{EVIDENCE FOR SEPARATE STREAMS}

Strong support for the separate-streams hypothesis is provided by five different lines of evidence: (1) improved ability to perform two concurrent verbal tasks when different input modalities are employed relative to the singlemode situation; (2) improved memory when different items are presented to two sensory modalities rather than one; (3) selective interference effects; (4) subjects' preference for and the greater efficiency of recall organized by modality than by time of presentation; and (5) the presence of short-term memory deficits that appear to be specific to the auditory or visual modalities. Studies falling into these categories are described below.

\section{Division of Attention Between Modalities}

In a large number of experiments on attention, shadowing (listening to a message and repeating it aloud) has been used as one of the two concurrent tasks to be performed. Concurrently with shadowing, the subject is asked to perform some other task, such as the detection or retention of certain words or letters. A number of experiments have shown that performance on the detection or memory task is better when the target items are presented to the visual modality than when they are presented auditorily (Allport, Antonis, \& Reynolds, 1972; Mowbray, 1964). Allport et al. (1972) ruled out alternate interpretations in terms of greater difficulty of visual items or a different tradeoff between shadowing and retention tasks for auditory and visual memory stimuli. Rollins and Thibadeau (1973), who reported results similar to those of Allport et al., found that relative to a listening condition, the requirement to shadow did reduce retention of visual wordsbut not to the same extent as it reduced retention of auditory words.

Kroll (1975) and his colleagues used a variation of the shadowing procedure, in which auditory memory items were presented as part of the shadowed message but in a different voice, so that the subject could distinguish them. In Kroll's procedure, attention was not divided between the shadowed items and the auditory memory items, whereas attention was necessarily divided between shadowed items and visual memory items. This should have produced an advantage for the auditory memory items. Even so, recall of visual items was higher than recall of auditory items, except at the very shortest retention interval, where recall was close to the ceiling for both modalities (Kroll, Parks, Parkinson, Bieber, \& Johnson, 1970; Parkinson, 1972; Parkinson, Parks, \& Kroll, 1971; Salzberg, Parks, Kroll, \& Parkinson, 1971). The procedure of having auditory memory items as part of the shadowed list and the finding of near-perfect recall of auditory memory items at the zero- and one-second retention intervals rules out an interpretation of the visual superiority in terms of perceptual difficulties for the auditory modality.

When the task performed concurrently with shadowing does not involve memory, it appears that visual presentation of the stimuli still produces better performance than does auditory presentation, while at the same time producing less interference with shadowing. Shaffer (1975) reported that a skilled typist could type one visually presented prose message and at the same time shadow a different auditorily presented prose message without exhibiting a decrement in the typing relative to the noshadowing condition. If the typed prose message were auditory rather than visual, the subject could not perform the dual task without producing pauses or errors. Dennis (1977) required subjects to shadow or to listen silently to an auditorily presented prose message while at the same time monitoring an auditory or visual list of words for targets specified by category membership. There were more shadowing errors and more misses on the detection task when the word list was presented auditorily than when it was visual. Rollins and Hendricks (1980) reported three experiments, in which subjects monitored sequences of auditory or visual words for targets while at the same time processing an auditory message. For all auditory processing tasks, detection of auditorily presented targets was 
much lower than detection of visually presented targets, and shadowing performance was impaired more by monitoring concurrent auditory words than by monitoring concurrent visual ones. Rollins and Hendricks (1980) concluded "that the visual and auditory modalities can process verbal material independently and without interference with each other ... at least to a level that permits some semantic analysis of words in each message"' (p. 106).

Treisman and Davies (1973, Experiment 2) compared monitoring without shadowing of two simultaneous auditory lists of words or two visual lists to a condition in which the two lists were presented in different modalities. Stimuli were presented on all four channels on all trials, so that peripheral masking was equated in all conditions. For both physically and semantically defined targets, detection was much better when the two competing messages were in different modalities. Treisman and Davies concluded that "there is clearly some modalityspecific perceptual capacity that cannot be redeployed to inputs in another modality when required. This means that there is effectively more capacity available when two modalities are monitored than one" (p. 113).

The literature on dual-task performance shows clearly that it is easier to divide attention between two concurrent tasks requiring processing of verbal stimuli when the stimuli are presented to the auditory and visual modalities than when all stimuli are presented to one modality. The apparent increase in processing capacity when two modalities are used is not simply due to perceptual mechanisms that process physical properties of items, because the difference between single- and dual-mode performance is found when semantic processing is required. Furthermore, the difference cannot be attributed to greater peripheral masking in the single-mode condition, because the dual-mode presentation still produces better performance when peripheral masking is equated in all conditions. It seems that there are modality-specific processing resources at both the perceptual and the semantic levels such that attention can more easily be divided between two modalities than between two messages in a single mode. The hypothesis of modality-specific processing resources that seems necessary to account for modality effects in dual tasks is entirely consistent with the separatestreams hypothesis. One has only to assume that the separate processing streams draw upon different pools of resources.

\section{Recall from One or Two Modalities in Memory}

If there are separate processing streams for auditorily and visually presented items in short-term memory, it should be possible to show that retention is greater if information is presented to two modalities than when only one mode is used. Although early attempts to demonstrate the effect proved disappointing (Murdock \& Carey, 1972; Murdock \& Walker, 1969), more recent work has shown that there is indeed an increase in the amount retained when two input modes are used in short-term memory tasks. Throughout the following discussion, the term mixed mode will refer to lists containing both auditory and visual items, with the items presented in sequential order; bisensory presentation will be the term used for lists in which different items are presented simultaneously to different sensory modalities.

Although Broadbent (1956, Experiment 1) did not emphasize his finding, he did obtain evidence that a bisensory presentation of six items produced higher recall than did single-mode presentation. When the three visual items were all presented simultaneously and the three auditory items were presented sequentially but at the same time as the visual, recall in the bisensory condition (95\%) was actually higher than recall of six sequential auditory digits $(90 \%)$ or of six simultaneously presented visual digits (78\%). Studies using the split-span task were carried out by Treisman and Davies (1973, Experiment 1) and by Hede (1980). Treisman and Davies found that recall was higher after bisensory presentation of two verbal sequences than after either dichotic auditory presentation or visual presentation. Hede (1980) reported higher recall in an experiment with bisensory presentation of stimuli than in a similar experiment with dichotic presentation.

Perhaps the most thorough and controlled study on the question of single-mode versus dual-mode memory was presented by Martin (1980). In a single trial, 16 words were presented as four sets of 4 simultaneous words; each set included 2 informative and 2 uninformative words. Retention of only the informative words was tested; the filler words were presented to equate peripheral masking in all conditions. The informative words were presented auditorily (left and right ears) to some subjects, and visually (left and right visual fields) to other subjects. For the remaining subjects, one informative word in each set was presented auditorily and one visually (bisensory presentation). When the target items were defined by a physical property, recall after bisensory presentation was higher than after single-mode presentation. When target items were defined on the basis of semantic category, precuing subjects as to which set of items was to be reported eliminated the difference between single- and dual-mode conditions, but the difference was still large in the postcuing situation. When the subjects had to report all the items of the specified category, dual-mode presentation produced higher recall than did single-mode presentation. Martin concluded (p. 110) that "the data appear to require the conclusion that at least some central processing capacity is modality-specific in nature."

The most recent experiment addressed to the issue of using two sensory modalities to increase retention was carried out by Frick (1984). In the dual-mode condition, he presented four visual digits simultaneously and then presented the auditory items sequentially. In the singlemode conditions, the visual items were all presented simultaneously, and the auditory items were presented sequentially; but both the auditory and the visual items were grouped by fours. When the subjects were instructed to report the auditory items before the visual, Frick found that the number of items correctly recalled was higher in 
the dual-mode condition than in either the pure auditory or the pure visual condition. He did not, however, find this improvement when the visual digits were reported first.

In general, it seems that short-term retention can be improved by presentation of items to two sensory modes rather than one. Recall levels in the dual-mode conditions are not equal to the sum of single-mode recall levels, so that there is no evidence for additivity of capacities of the auditory and visual stores or processing streams. Given the problems involved in separating a possible long-term memory contribution to performance in short-term memory tasks, and given the likelihood of output interference for items reported later in recall, it would seem to be an impossible task to demonstrate additivity of auditory and visual capacities. Neither does the separate-streams hypothesis necessarily predict additivity if one considers that there may be mutual interference between the $P$ code for auditory items and the $\mathbf{P}$ code for visual items. Nevertheless, the observed improvement in short-term retention produced by the concurrent use of the two modality-specific processing streams is consistent with the hypothesis of separate processing streams that call upon separate pools of resources.

In all of the experiments in which dual-mode recall was found to be higher than single-mode recall, the subjects were permitted or required to recall items from the two modes separately. They were not required to retain information about the relative order of items in different modalities. When subjects are forced to recall items from a mixed-mode list according to a strict temporal order, recall is lowered relative to a condition in which subjects order items within each modality (Penney, 1980). In immediate serial recall, when subjects must recall the actual order of items, recall from mixed-mode lists has been shown to be lower than recall from single-mode lists (Fell \& Laughery, 1969). The separate-streams hypothesis can account for the apparently contradictory findings in the following way: If auditory and visual items are processed in separate streams, integration of the two streams is likely to be difficult, and subjects will not easily remember the order of items presented in different sensory modalities. Recall from mixed-mode lists is therefore worse than that from pure-mode lists. This situation contrasts with those experiments in which the subject can organize recall from bisensory or mixed-mode lists according to presentation modality. In the latter case, the subject can make use of the additional processing capacity made available when two modes are used for input; and recall is higher than when only one input modality is used.

\section{Selective Interference Effects}

There is substantial evidence that auditorily presented verbal stimuli selectively interfere with retention of previously presented auditory-verbal items, but the situation for the visual modality is not quite as clear. The separatestreams hypothesis would receive strong support if it could be shown that visually presented verbal distractors interfere with retention of other visual-verbal items more so than do the same distractors presented auditorily. It seems that visually presented verbal stimuli are recoded through silent articulation into a phonological code for rehearsal (see Baddeley, 1983, 1986), and that this code is susceptible to interference from auditorily presented distraction. Nevertheless, under suitable conditions, a selective visual interference effect can be demonstrated. In the next section, I will review the evidence for the auditory and visual selective interference effects, including suffix effects, and attempt to show how the two modalities differ.

Auditory Suffix Effects. The most thoroughly investigated example of specific auditory-verbal interference is the suffix effect in immediate serial recall. The suffix is a redundant verbal item added to the end of the list of memory items. Even when the suffix is the same word on every trial and subjects can ignore it or treat it as a cue to begin recall, the suffix produces a substantial decrease in recall of items near the end of the list, much as an additional memory item does (see Crowder, 1967, Experiment 3; Dallett, 1965). What is intriguing about the auditory suffix effect is the large amount of interference produced by a single verbal item that carries no memory load. No matter how hard the subjects try, it seems that they cannot block out the suffix and prevent its interfering with retention.

There appears to be a strong, but not perfect, relationship between the suffix effect and the original modality effect: Where one is found, the other can usually be demonstrated as well. The superiority of auditory over visual presentation is found for up to five serial positions at the end of the list in immediate serial recall (e.g., Murray, 1966); the suffix effect has a similar extent (e.g., Penney, 1979). Engle (1974) compared suffix and modality effects in free and serial recall and found that, in both tasks, the serial positions affected by presentation modality were also those affected by the suffix. Murdock (1967) reported a modality effect that extended over a large portion of a 10-item list in probed recall; Penney (1982b) demonstrated that the suffix effect had a similar extent. Finally, Crowder (1971) and Darwin and Baddeley (1974) used nonsense syllables consisting of an initial consonant and a vowel sound. They found both modality and suffix effects when the syllables differed in the vowel sound but not in the initial consonant, but neither effect was found when the syllables had the same vowel sound but different initial stop consonants.

One of the strongest arguments in favor of the PAS model was that it accounted for the co-occurrence of modality and suffix effects. The hypothesis that auditory sensory information persisted in a limited-capacity memory store provided an explanation of the transient auditory superiority; the suffix effect was attributed to the suffix's gaining entry into the sensory store and either displacing the existing sensory information or disrupting access to it. Although the PAS model was based primarily on results obtained with immediate serial recall, the observation of both suffix and modality effects in other tasks strengthened the view that the PAS was a structural part of the 
system, and not merely a manifestation of some taskspecific strategy.

More recently, the situation with respect to suffix effects has been complicated by reports of suffix effects in modalities other than audition. Suffix effects have been reported when both memory items and the suffix were presented in American Sign Language (Shand \& Klima, 1981), or when stimuli are presented in the tactile modality (Manning, 1980; M. J. Watkins \& O. C. Watkins, 1974). Visual suffix effects have been reported with lip-read stimuli (Campbell \& Dodd, 1980; Greene \& Crowder, 1984), and with various kinds of graphically presented verbal stimuli (Hitch, 1975; Kahneman \& Henik, 1977; Manning, 1980; Manning \& Gmuer, 1985). The nature of recency and suffix effects with lip-read stimuli suggests that there may be a close relationship between verbal information acquired through hearing and that acquired through lipreading. Crowder (1983) presented a modification to the PAS model intended to accommodate the effects of lipreading and silently mouthing memory items and suffixes. However, Crowder's revised model does not account for either the visual suffix effects described in the next section or the tactile suffix effects. Furthermore, Crowder's model cannot account for the suffix effects with musical stimuli that have been reported recently (Greene \& Samuel, 1986; L. A. Roberts, 1986).

Other investigators have also attempted to provide a unified account of both auditory and nonauditory suffix effects. Kahneman (1973) proposed an account of the suffix effect in terms of preattentional grouping. Campbell and Dodd (1980) suggested that stimuli changing more or less continuously over time may be processed differently from static stimuli such as visually presented words. It is this property of continuous change that they suggested was critical in producing recency and suffix effects. Shand and Klima (1981) proposed that the critical factor in producing suffix, recency, and modality effects is whether or not the input is in a primary linguistic code.

All of these hypotheses may have some value in the identification of factors that influence suffix effects, but none of these hypotheses accounts for all suffix effects. Kahneman's (1973) hypothesis does not accommodate the work with lip-read and silently mouthed stimuli very well, and in a direct test of Kahneman's hypothesis involving temporal grouping of auditory stimuli (Penney, 1978), no supporting evidence was found. Crowder (1986) presented clear evidence that the changing-state quality of stimuli was not responsible for the modality effect. He found that having visual stimuli develop over time did not produce any substantial improvement in recall relative to the more usual "instantaneous" (i.e., approximately $100-\mathrm{msec}$ ) presentation. However, subject vocalization of the stimuli did produce a large improvement in recall of the last two or three list items, a finding that replicated the results of earlier work. Furthermore, it is difficult to see how the changing-state hypothesis would account for suffix effects observed when piano notes were the memory stimuli
(Greene \& Samuel, 1986). The primary linguistic hypothesis cannot account for the existence of a tactile suffix effect when the memory stimuli are taps to different fingers (M. J. Watkins \& O. C. Watkins, 1974), nor for the visual (graphic) suffix effects described in the next section on visual interference effects. Neither can the primary linguistic hypothesis account for suffix effects found with melodies (L. A. Roberts, 1986) or environmental sounds (Rowe \& Rowe, 1976). Not only do these three hypotheses-the changing-state hypothesis, the primary linguistic hypothesis, and Kahneman's preattentive grouping hypothesis-fail to account fully for all the suffix effects observed, they do not even begin to account for the various modality effects.

Rather than view suffix effects as a manifestation of an auditory sensory store, I think it is more productive to consider suffix effects (and other selective interference effects) as short-term memory phenomena. Within shortterm memory, many different kinds of information are processed and retained. Retention is an active process requiring the generation and maintenance of various codes. If the subject must process the suffix, and if the same processing mechanisms are already being used to capacity for the retention of some other information, the suffix will necessarily produce interference. The amount of interference will depend on the similarity of suffix and memory items and the extent to which the suffix requires the same processing mechanisms as the memory items.

It would be nice if all suffix effects had the same underlying mechanism, but I think it unlikely. If different sensory modalities process different kinds of information in different ways, and if suffix effects, or other selective interference effects, illustrate interference within a sensory modality, the mechanisms by which the interference occurs may differ for different modalities. For example, to obtain a visual suffix effect with written material, it seems necessary either to have a concurrent auditory task (Penney, 1974b) or to use simultaneous presentation of all memory items (see the next section on visual interference effects.) Hitch (1975) has also presented evidence that interpolating an irrelevant digit between list items eliminated the visual suffix effect but not the auditory. The available evidence indicates that auditory and visual suffixes operate quite differently. Whether suffix effects with lip-read and mouthed stimuli reflect the same underlying mechanism as the auditory suffix effects is more difficult to answer, for less data are available. Reports of any differences at all among lip-read, mouthed, and auditory stimuli would rule out identical mechanisms. Instead of emphasizing the similarities between suffix effects in different modalities, the separate-streams hypothesis suggests that it might be more productive to look for differences.

The position taken here with respect to the auditory suffix effect is that presented by Penney (1985). Within the auditory stream, sensory information persists for a period of up to $60 \mathrm{sec}$ (Engle \& Roberts, 1982). This sensory information (or "echo") underlies both the suffix 
and the modality effects: the "echo" or the A code provides valuable information that contributes to recall of auditory but not visual stimuli, and the suffix impairs retention of this sensory information. My view of the suffix effect differs from that of Crowder and others in several important respects. Like Baddeley and Hull (1979), Balota and Engle (1981), and Morton (1976), I believe that there are two mechanisms underlying the suffix effect, one that is apparent for the terminal list item only, and one that is found over several items near the end of the list, including the terminal list item. These other investigators consider only the terminal suffix effect to reflect the operation of the sensory store, while the preterminal suffix effect is thought not to be modality-specific. In contrast, my view is that the preterminal suffix effect is modalityspecific-both the number of serial positions manifesting the modality effect and the length of time over which modality and suffix effects occur support this conclusion. (See Penney, 1985, for further arguments and evidence.) The terminal suffix effect reflects a loss of distinctiveness of the terminal item due to the fact that, in the suffix condition, the last list item is no longer the final item in the sequence.

Auditory selective interference effects. In a number of studies, evidence of a selective impairment in recall of auditorily presented information by auditory distraction has been found, but retention of visual memory items seems to have been affected equally by both auditory and visual distractors. For example, in a study by Broadbent, Vines, and Broadbent (1978), fifteen words were presented either auditorily or visually, and they were recalled either immediately or after an interval filled with the copying of two-digit numbers that were presented either auditorily or visually. The modality of the distractor task had no effect on recall of items in the first 10 serial positions, but large effects were found for the last 5 serial positions. Compared to no-distractor and visual distractor conditions, the copying of auditory digits reduced recall of recent auditory items. Both distractor tasks reduced recall of visually presented words. Similar results have been reported by Gathercole, Gregg, and Gardiner (1983), Rönnberg and Ohlsson (1980), and O. C. Watkins and M. J. Watkins (1980).

Selective interference with retention of auditory memory items has also been demonstrated when it is the sound of the rememberer's own voice that is the source of the interference. Elliott and Strawhorn (1976) used auditory or visual presentation of word triads in a Peterson task followed by either a silent or a vocalized distractor task. For both auditory and visual memory items, vocalized distraction disrupted recall more than did the silent distractor activity, but the effect was greater for auditory memory items. Gardiner, Thompson, and Maskarinec (1974, Experiment 3 ) presented lists of 15 words auditorily or visually, for either immediate recall, or recall after $30 \mathrm{sec}$ of either counting backwards aloud or silent copying of visually presented digits. Although Gardiner et al. did not directly compare the effects of the two interference tasks, one can see from their serial position curves that the counting task had a greater deleterious effect on recall of terminal auditory items than the silent copying task did. For visual memory items, there appeared to be little difference between the two distractor tasks.

The experiments described above have produced consistent results for the auditory modality. When auditorily presented memory items or vocalized visual items are followed by a set of distractor items, auditory distractors produce much more interference than visual distractors do. For visual memory items, distractors presented to either modality reduce recall relative to a control condition. Clearly, the auditory selective interference effect is large and robust, but the analogous visual effect is not found in most studies. However, a selective visual interference effect for verbal items has been demonstrated under certain experimental conditions. Examination of the conditions under which the visual interference effect occurs shows how the short-term memory mechanisms for visually presented verbal items differ from those for auditory items.

Visual selective interference effects. For my $\mathrm{PhD}$ dissertation research (Penney, 1973), I used a four-channel presentation (Murdock, 1971) that allowed the simultaneous presentation of four items: two auditory items to different ears, and two visual items. In the first experiment of my dissertation project (Penney, 1974b), either two or three sets of four simultaneous words were presented to subjects for immediate recall. The subjects were cued after list presentation to recall only auditory words, only visual words, or both. Cue modality was crossed with presentation modality of the memory items. A surprising finding was the crossover interaction between cue modality and target mode, whereby recall was lower if cue and target modalities were the same. The effect was found for both auditory and visual targets. The visual interference effect was replicated in another experiment containing two-channel bisensory lists (Penney, 1973, Experiment 4).

In an earlier experiment, Margrain (1967) reported a selective interference effect produced by response modality. Different auditory and visual digits were presented simultaneously for immediate recall in a mode-by-mode order, with some subjects recalling orally and others writing their responses. When auditory items were reported after visual items, spoken report produced lower recall than did written report. For visual items reported after auditory items, written report was worse than spoken. Margrain concluded that "there may initially be two shortterm stores: one for visual material and one for auditory, since interpolated activity of one kind damaged the retention of earlier material of that kind, more than material of the alternative type"' (p. 113).

Margrain's work and my own indicate that a selective visual interference effect can be obtained when bisensory presentation of information is used and the subject has to remember both the auditory and visual items. The finding of a visual interference effect with simultaneous 
presentation of auditory and visual stimuli but not with single-mode presentation is consistent with the hypothesis that visually presented verbal items are normally retained in the $\mathbf{P}$ code. Concurrent presentation of auditory stimuli with the visual memory items appears to disrupt the generation of the $\mathbf{P}$ code and forces the subject to rely on a visually based code that is susceptible to interference from subsequent visual stimuli. Kroll (1975) summarized a lot of his own work and also concluded that a concurrent shadowing task prevented the articulatory recoding of visual stimuli and forced subjects to maintain a visually based memory code.

If the $\mathbf{P}$ code normally underlies retention of visually presented stimuli, it should be possible to demonstrate a visual interference effect when recoding is suppressed. Martin and Jones (1979) reported results that support this prediction. They presented lists of words for free recall, and during list presentation, the subjects either engaged in irrelevant articulation or did not. If the subjects in the irrelevant articulation condition had difficulty converting the visual items into the $\mathrm{P}$ code or in retaining recoded items, they could be expected to have relied on a visual code that was susceptible to interference from visually presented distractor stimuli. In Experiment 2, Martin and Jones found that for recency items, the visual distractor task produced much greater interference in the irrelevant articulation condition than in the no-articulation condition. In contrast, an auditory distractor produced equal interference for both irrelevant articulation and silent reading conditions. In their fourth experiment, Martin and Jones (1979) directly compared auditory and visual distractors for irrelevant articulation and no-articulation conditions. For the last three serial positions, the visual distractor lowered recall more than did the auditory distractor when the subjects engaged in irrelevant articulation, but the reverse effect was found in the no-articulation condition. The data of Martin and Jones suggest that irrelevant articulation disrupts the generation or maintenace of the $P$ code and forces subjects to rely on a visual code that is subject to visual interference.

There have also been reports of selective visual interference effects even when subjects do not engage in a concurrent task. Experiments in which a selective interference effect has been found have either involved the Peterson distractor task (Hopkins, Edwards, \& Cook, 1973; Marcer, 1972; Proctor \& Fagnani, 1978) or else tested serial recall with simultaneous presentation of the visual stimuli. Hopkins et al. (1973) reported that with visually presented distractors, recall of auditory words exceeded that of visual words, but with auditory distractors, the reverse was found. Proctor and Fagnani (1978) found that recall of the visual trigram was higher if the distractor number was presented auditorily rather than visually. (Presentation modality of the digits had no effect on recall of auditory trigrams, probably because the counting aloud produced maximum interference.)

Why was there an effect of distractor modality in the experiments with the Peterson task but not in the experi- ments with free or serial recall that were described in the section on auditory selective interference effects? One possible explanation is that in the experiments by Hopkins et al. (1973) and by Proctor and Fagnani (1978), the subjects responded orally to distractor items presented during the retention interval. (Marcer did not say whether subjects counted backwards aloud or silently, but the usual procedure was to have subjects count aloud.) To the extent that the subjects had recoded the visual items, the oral responses might have interfered with retention of the $P$ code. If so, the subjects would then have had to rely more heavily on the visually based code, which would have been subject to interference from the visually presented distractors.

Another factor that might have produced the visual interference effect in the experiments by Proctor and Fagnani (1978) and by Marcer (1972) is the use of simultaneous presentation of visual stimuli. In two further experiments in which a selective visual interference effect was found (Frick, 1985; Merikle, 1976), simultaneous presentation of visual stimuli was used. Merikle (1976) presented an array of seven letters for $100 \mathrm{msec}$, followed immediately by an auditorily or visually presented digit that indicated which letter was to be recalled. For all positions of the target letter, the auditory probe produced higher recall than did the visual. Merikle ruled out an iconic memory explanation and concluded that "visual information may be stored in a short-term visual memory system which is not disrupted by a patterned visual stimulus ... but is disrupted by an attention-demanding visual stimulus" (p. 201).

Frick (1985) measured digit span for simultaneous and sequential visual presentation and auditory presentation of digits, with visual presentation always accompanied by irrelevant articulation. Frick also investigated the effects of speaking or writing a response prefix upon digit span for the various presentation modes. As expected, the spoken prefix reduced auditory digit recall relative to a no-prefix control, and a written prefix had no effect. For sequential visual presentation, neither a spoken nor a written prefix had any significant effect; but for the simultaneous presentation, the written prefix impaired recall more than did the spoken prefix. Frick's experiment shows that a response prefix produces modality-specific interference in both the auditory and the visual modalities, and that the visual interference effect did not occur with completely sequential presentation of the memory items.

Proctor and Fagnani (1978), Marcer (1977), Merikle (1976), and Frick (1985) all found a visual interference effect in their experiments, and all of them employed simultaneous visual presentation of several memory items. Given the difficulty of demonstrating a selective visual interference effect when visual items are presented sequentially, the large effect of a single visual distractor item observed by these investigators is very interesting. It would appear that simultaneous presentation of visual stimuli can be added to bisensory presentation and irrelevant articulation as factors that induce the subject to main- 
tain a visually based code. It is worth noting as well that a visual suffix effect has been reported when the visual memory items and suffix were all presented simultaneously (Frick \& De Rose, 1986a, 1986b; Kahneman, 1973; Kahneman \& Henik, 1977).

There have been reports of visual suffix effects in serial recall with completely sequential presentation of list items and suffixes (Hitch, 1975; Manning, 1980; Manning \& Gmuer, 1985). Hitch required subjects to recall orally where a written report was more typical; and Manning used dynamically changing visual stimuli rather than the usual visual presentation. Whether these factors were critical in producing the visual suffix effect is not yet clear. What is clear, however, is that visual suffix effects appear to be quite different from the auditory suffix effects.

Summary of selective interference effects. The finding of both auditory and visual selective interference effects provides further evidence for the separation in processing of auditorily and visually presented verbal items in short-term memory. The auditory interference effect is extremely robust, but the visual effect is demonstrable only under certain circumstances. The presentation of auditory memory items concurrently with the visual, the requiring of irrelevant articulation by the subjects during presentation of visual memory items or possibly during the retention interval, and the simultaneous presentation of visual memory items all promote the use of a visual code for retention, and this code is susceptible to interference from a subsequent visually presented verbal distractor stimulus. When the subject is permitted to represent visual stimuli in the phonological code, a selective visual interference effect is not likely to be found.

\section{Organization by Modality}

A fourth line of evidence supporting the hypothesis that auditorily and visually presented verbal items are processed in separate streams is the finding that in immediate recall, presentation modality provides a strong basis for organization. Not only can subjects organize their recall by modality when instructed to do so, it appears that organization by modality is the preferred or optimal organizational scheme. The evidence also suggests that the modality organization is not merely a reflection of some discretionary strategy adopted by subjects, but rather an inherent property of the memory system.

There are a number of reports that subjects prefer to recall mixed-mode lists according to presentation modality, or that such an organization is more efficient than recall according to temporal order (Broadbent \& Gregory, 1961; Murdock \& Walker, 1969; Nilsson, 1973, 1974). Rönnberg, Nilsson, and Ohlsson (1982) examined output organization in lists that contained words in two sensory modalities, two languages (Swedish and English), or two semantic categories. Organization by modality was consistently higher in mixed-mode lists than was organization by language in mixed-language lists. Modality organization was also higher than organization by category in mixed-category lists. It seems that presentation modality provides a very powerful dimension for organization in short-term memory.

Penney (1980) presented lists of 10 digits such that presentation modality changed after every second digit. Some subjects were instructed to report the digits in their correct order within each modality; others were required to report the digits in the actual order of presentation, disregarding presentation modality. Strict serial report produced lower recall than did reporting the items separately by modality. It seems that the subjects had difficulty ordering items presented to two different sensory modes. A later study (Penney, 1982a) ruled out the possibility that the higher recall with a mode-by-mode report order rather than with strict serial recall was due to some kind of chunking strategy.

Penney and Butt (1986) compared the relative importance of temporal adjacency and identity of probe and target modalities in determining the effectiveness of a recall probe. Lists contained 10 digits, with presentation modality changing after every second digit. At the end of the list, 1 digit was repeated as a probe or recall cue. In one condition, the subjects were instructed to report the digit that had been presented in the list immediately after the probe item. The probe item and target could have been presented either in the same modality or in different modes. Penney and Butt found (as did Murdock, 1967) that recall was much higher if both probe and target had been auditory than if either or both had been visual. In the second condition, subjects were instructed to report the next item after the probe but in the same modality. In some cases, this meant that two items in the other mode intervened between probe and target items in the list. When this occurred, the probe was called a temporally distant probe. Higher recall was obtained for a temporally distant probe than for a temporally adjacent probe that was not in the same modality as the target. It seems that presentation modality was more important in determining probe effectiveness than temporal contiguity was.

A number of studies have examined output order for bisensory lists (lists in which different memory items are presented simultaneously to ear and eye). In general, the results are similar to those found for mixed-modality lists-recall by modalities is preferred and is more efficient. Madsen, Rollins, and Senf (1970) reported a series of experiments examining retention of bisensory stimuli. In general, the mode-by-mode recall order was preferentially adopted by the subjects, and a pair-by-pair order was used only at the slowest rate and only if the subjects had not previously experienced the fastest rate. Hede (1973) also found a strong preference for a modality report order for bisensory lists when the presentation rate was fast. Penney (1974b) used a four-channel presentation and found that when the subjects had to report both auditory and visual items, they tended to recall by modality with the visual items reported first. When subjects are instructed regarding the order of report, the usual finding is that at the fast rate (.5 sec per pair), the modality recall order produces higher recall, whereas at the slower 
rate, the pair report order is better (Madsen et al., 1970; Rollins, 1972; Senf \& Rollins, 1971). These effects seem to hold, whether the subjects are instructed about report order before list presentation or after (Madsen et al., 1970, Experiment 7; Senf \& Rollins, 1971).

In the dichotic split-span task, category of stimulus item seems to function as effectively in defining a channel as does ear of presentation to produce a channel-by-channel report order. Gray and Wedderburn (1960) and Yntema and Trask (1963) presented two classes of items (e.g., words and digits) such that one ear heard a word, then a digit, and then another word, and the second ear heard a digit, a word, and then another digit. Recall ordered by stimulus class was actually higher than recall ordered by ear of presentation. Madsen et al. (1970, Experiment 2) attempted to replicate this effect by using the eye and the ear for the two channels, rather than the two ears. They found that when type of stimulus material alternated between sensory modes, subjects virtually never recalled by stimulus class, but instead chose the modality report order. Hede (1973) examined free recall of bisensory lists and compared it to recall organized according to modality, temporal pairings (one auditory and one visual item), and stimulus class (digits, words, and letters). Under free recall, 35 out of the 36 subjects tested recalled the items by modality, with most subjects recalling the visual items first. When the subjects were instructed regarding report order, recall ordered by modality was consistently higher than recall ordered by temporal pairs or stimulus types.

In summary, when subjects are presented with lists containing different items presented in the auditory and visual modalities, the preferred recall strategy is to report one modality first, and then to attempt recall of items in the other mode. The modality recall order is found for bisensory lists with auditory and visual items presented simultaneously, and for mixed-mode lists with items presented one at a time. The finding of a modality report order with mixed-mode lists makes an interpretation in terms of switching attention between modalities unlikely, for items in different modalities are never simultaneous. An attentional explanation might be plausible if the modality report order were obtained only with bisensory lists and only at fast presentation rates. Penney and Butt's (1986) results for the comparison of temporally distant probes with probes that had been temporally adjacent to the target but in the other sensory modality are also incompatible with an attentional interpretation. Organization according to modality overrides organization according to time of arrival-the organizational scheme one would expect if rehearsal were the dominant mechanism of retention. Presentation modality provides a stronger organization than language or category (Rönnberg et al., 1982), and modality outweighs semantic factors in governing output order in bisensory tasks (Hede, 1973; Madsen et al., 1970). The evidence that presentation modality is more important in determining recall order than is time of arrival or meaning suggests that the organization im- posed by presentation modality is stronger than organization along other dimensions. The difficulty subjects experience in organizing mixed-mode or bisensory lists along some dimension other than presentation modality suggests that modality organization is not a strategy that can be abandoned at will, and that modality organization is fundamental to short-term memory.

\section{Selective Memory Deficits}

A number of case studies have been published that demonstrate a severe impairment in retention of auditorily presented verbal material. There is usually a retention deficit for visually presented material as well; but it is not nearly as large as the auditory deficit, and recall of visually presented items exceeds that of auditory items. Two cases (K.F. and P.V.) have been studied in more detail than the other cases and so will be summarized here. Case K.F. is described in papers by Shallice and Warrington (1970), Warrington, Logue, and Pratt (1971), Warrington and Shallice $(1969,1972)$. Case P.V. is described in a paper by Basso, Spinnler, Vallar, and Zanobio (1982), with further work reported by Vallar and Baddeley (1984). Other case histories have been reported by Saffran and Marin (1975), Strub and Gardiner (1974), and Tzortzis and Albert (1974).

The most obvious deficit characterizing both K.F. and P.V. is the extremely low auditory digit span. Neither patient was able to repeat reliably a string of two auditorily presented items, but both did perform better when visual presentation was used. In a free recall task, K.F. produced a recency effect confined to the final serial position; P.V. produced no recency effect at all. Both patients exhibited severely impaired retention of auditory letters in a Peterson distractor task, but much higher retention of visually presented letters. Learning and language comprehension were virtually normal.

Shallice and Warrington (1977) reviewed the published case histories (except P.V.'s) and concluded that the observed performance deficit is best explained as an impairment in auditory-verbal short-term memory. Vallar and Baddeley (1984) attributed the impairment in the case of P.V. to the phonological store. The separate-streams hypothesis accounts for the deficit manifested by these patients in terms of impaired formation or retention of $A$ and $P$ codes. In the case of auditory presentation, the "echo" (the A code) that persists and is so useful for normal subjects was not available to these subjects; hence the very low auditory digit span and minimal recency effects. In the case of visual presentation, performance was much improved because the subjects could rely on the visually based code, but retention was lower than normal, because the optimal code for visual items (the $\mathrm{P}$ code) was not available.

If the auditory and visual processing streams are separate, it should also be possible to find analogous cases of performance deficits attributable to impairment of the visual subsystem. Warrington and Rabin (1971) measured 
the visual span of apprehension (actually the memory span for different types of material) in patients with different types of localized cerebral lesions. Patients with posterior left hemisphere lesions manifested a reduced visual span relative to patients with right posterior, left temporal, or left anterior lesions. Correlations between the memory spans for different types of visually presented material (including one set of nonverbal material) were high, but correlations between visual span and auditory digit span were much lower and in many cases not significant. Warrington and Rabin concluded that their findings suggest a short-term visual memory deficit.

\section{Summary of the Evidence for Separate Streams}

Evidence has been presented to support the separatestreams hypothesis - the hypothesis that verbal material presented auditorily and visually is processed in different parts of the memory system and by different mechanisms. The evidence pertains to five main findings: (1) the superior performance on concurrent tasks when stimuli are presented to two modalities rather than one; (2) higher recall when two presentation modalities are used instead of one; (3) the observation of both auditory and visual selective interference effects; (4) the strength and pervasiveness of organization by modality and the apparent difficulty of overriding the modality organization; and (5) the finding of modality-specific deficits in short-term memory. Any one of these findings could probably be explained without reference to separate processing streams, but the overall picture is convincing. The hypothesis of separate processing streams makes sense out of dozens of different experiments. Furthermore, the agreement among different investigators on the theoretical account of their findings is impressive. A number of direct quotations were cited above to show how different people have come to the same conclusion regarding the extent of modality-specific processing or storage systems in memory. It is not merely that modality effects appear in a variety of memory tasks, but also that the observed effects of presentation modality are all consistent with an explanation made in terms of separate processing subsystems for the auditory and visual modalities in shortterm memory.

\section{ALTERNATE ACCOUNTS OF MODALITY EFFECTS}

\section{The Auditory Sensory Store}

The first theoretical account of the original modality effect was the PAS model of Crowder and Morton (1969). The PAS model proposed that an auditory sensory store (called, as stated above, the precategorical acoustic store, or PAS) maintained unprocessed acoustic information about the most recent item for a second or two. This sensory information lasted just long enough to supplement the information in short-term memory for the last few items in the list. Because the analogous visual sensory store decayed within less than a second, there was no supplemental visual information. The higher recall of audi- tory items at the end of a list could therefore be accounted for by the persistence of information in the PAS. In addition, the PAS model was able to account for the interfering effects of a stimulus suffix in that the suffix either displaced the information in the PAS about the last list item or disrupted access to that information. Crowder revised and elaborated on the original PAS model in 1978 and 1983. In the 1978 paper, Crowder proposed three mechanisms contributing to the suffix effect: (1) integration of the last item and the suffix at very short suffix delays, (2) backward masking through lateral inhibition at intermediate delays, and (3) readout of information from the PAS to short-term memory at longer delays. The modification outlined in the 1983 paper allowed information about articulatory movements to contribute to the selection of auditory features in the PAS. This modification was included to enable the PAS model to account for the effects of lipreading and of the silent mouthing of memory items and suffixes.

Evidence against the 1978 version of the model was provided by O. C. Watkins and M. J. Watkins (1982) and by Frankish and Turner (1984). Watkins and Watkins were unable to replicate the larger effect of a single as opposed to a triple suffix, an effect Crowder interpreted as evidence for lateral inhibition, and they pointed out a prediction of the theory that was contrary to existing data. Frankish and Turner presented an alternative interpretation of Crowder's 1978 data on the effects of suffix delay and reported an effect of suffix delay for very rapidly presented list items that was directly opposite to the effect Crowder found. Whenever Crowder's 1978 model has been directly tested, it has not held up well at all.

In my view, neither the 1978 nor the 1983 revisions of the PAS model enable it to account for the range of modality and suffix effects described here. For example, the results of the divided attention studies would be compatible with a sensory-stores view only if the procedure comprised discrete trials such that the subject could store the auditory input for a few seconds in the auditory sensory store, process the visual items, and then retrieve the auditory items from sensory memory and process them. Reports of visual interference effects that do not seem to be strictly analogous to the auditory interference effects suggest that there are more extensive differences between the auditory and visual modalities than the PAS model would allow. Finally, if auditorily and visually presented items are held in a common verbal short-term store and are distinguishable only because of a tag or markers, it is difficult to see why the tendency to organize recall according to presentation modality should be so strong. All these effects suggest a mechanism that is more than a short-lived sensory store.

When the PAS model was first published, there was some indication that the estimates of the capacity and duration were not appropriate; more recent research on modality and suffix effects confirms the discrepancy. In free recall, modality and suffix effects extend over about six items (see Engle, 1974). In serial recall-the task on which the PAS model is primarily based-the modality effect 
extends back from the end of the list over four serial positions (Madigan, 1971; Murray \& Roberts, 1968; Penney, 1979), and the suffix effect can affect as many as 6 items when recall is written (Penney, 1979, Experiment 3). Using a probed-recall task, Murdock (1967) found that the modality effect extended throughout a 10-item list as long as both probe and target were auditory, and Penney (1982b, Experiment 2) found a small suffix effect of similar extent. Routh (1976) obtained the auditory superiority throughout an 8-item list when subjects engaged in a concurrent writing task. If the PAS is hypothesized to contain information about only 1 or at most 2 items, it is difficult to see how the PAS model can account for suffix and modality effects that extend over 4 to 9 items. Such effects are simply not compatible with the capacity and time limits originally proposed for the PAS.

Evidence against the hypothesis that the sensory information underlying the modality effect persists only for 1 or $2 \mathrm{sec}$ was presented by Engle and Roberts (1982), by Gathercole, Gregg, and Gardiner (1983), and by O. C. Watkins and M. J. Watkins (1980). Engle and Roberts reported a modality effect in free recall when a 60 -sec empty interval intervened between list presentation and recall. A small modality effect was still obtained when the retention interval was filled with $60 \mathrm{sec}$ of a visual task; but $15 \mathrm{sec}$ of an auditory distractor task eliminated the modality effect. Consistent with the apparent 20 -sec duration of echoic information underlying the modality effect, M. J. Watkins and Todres (1980) and Balota and Duchek (1986) found that a suffix delayed by $20 \mathrm{sec}$ (where the interval was filled with a silent arithmetic task) reduced recall of the terminal list item. Overall, the effects of delayed postlist distractor tasks and suffixes indicate that the information underlying the modality and suffix effects, although extraordinarily persistent in time, is nevertheless highly susceptible to auditory interference.

Is it possible to rescue the PAS notion by enlarging the capacity of the sensory store and by extending the hypothesized duration of the sensory information? Whereas these modifications appear to be demanded by a number of findings, they are still not sufficient to provide a full account of all modality effects. M. J. Watkins (1972) and M. J. Watkins and O. C. Watkins (1973) found that the modality effect extended over the same number of words, regardless of the number of syllables in the words. This finding suggests that the extent of the modality effect is determined by the number of words and not by the amount of acoustic information. The word can hardly be the unit of storage in a precategorical or purely sensory store. Therefore, Watkins and Watkins argued, the modality effect must arise after word identification.

There is also some evidence consistent with a postcategorical interpretation of the suffix effect, or, at least, consistent with the existence of a postcategorical component in the suffix effect. Harris, Gausepohl, Lewis, and Spoehr (1979) and Salter and Colley (1977) found that the effect of a suffix upon the terminal list item was reduced if the suffix was related in some way to that terminal item. In the Salter and Colley study, the suffix was either a synonym of the terminal item or was unrelated to it; in the Harris et al. experiment, the suffix belonged to the same semantic category. If semantic factors can reduce the suffix effect, it seems that sensory information and semantic information must somehow interact in short-term memory.

Other evidence that there is a postcategorical component in the suffix effect comes from experiments showing that the distribution of suffix interference depends upon such factors as output order and rehearsal strategy. Manning and her colleagues (Manning \& Pacifici, 1983; Manning \& Turner, 1984) examined backward and circular (the last three items recalled first, then the remaining items recalled in order) recall orders and did not obtain the typical end-of-list suffix effect. Penney (1985) found that knowledge of list length and rehearsal strategy interacted. When list length was randomized and when subjects adopted a cumulative rehearsal strategy, the preterminal suffix effect was eliminated. Factors such as rehearsal strategy, knowledge of list length, and output order should not produce such large and extensive effects if a purely sensory or precategorical store is what underlies the modality and suffix effects.

A full account of the suffix and modality effects has to take into account findings which suggest that the information underlying these effects is sensory and precategorical as well as other findings which suggest that it is postcategorical. The apparent contradictions can be resolved within the framework of the separate-streams hypothesis. Auditory short-term memory is conceptualized as a processing stream in which acoustic properties of the items are processed as well as lexical and semantic information. The original modality effect is hypothesized to be due to the persistence of information in the A code (what has been called the "echo"), and the suffix effect is due to displacement of this information. The relationship between the $A$ and $P$ codes is not yet clear, but one hypothesis is that the acoustic information is organized according to higher level units (phonemes, syllables, or even words). Thus, sensory information is retained in the same part of the system (the auditory stream) as is other higher level information about the items, such as the meaning and the temporal properties. Semantic, articulatory, and acoustic information are all stored and processed together and can therefore interact.

Perhaps the strongest evidence that a sensory-stores hypothesis does not completely account for modality effects is the finding of a modality effect under conditions that would prevent the utilization of echoic information. Gardiner and Gregg (1979) and Glenberg (1984) used a task that combined free recall with distraction before and after every list item. Since the distraction task had both visual and auditory components, there is good reason to believe that the subjects could make little or no use of the echoic information of the type that appears to under- 
lie the modality effect in immediate recall. Even so, recall of the last few items was higher when they had been presented auditorily.

It is beginning to appear that the modality effect in immediate recall and the long-term modality effect react differently to certain variables. For example, Gregg and Gardiner (1984) reported no effect of phonological similarity of memory items on the long-term modality effect. This finding is to be contrasted with the large effects of phonological similarity on the modality effect in immediate recall (M. J. Watkins, O. C. Watkins, \& Crowder, 1974). Greene (1985) found that unlike the large and reliable modality effect found in immediate serial recall, the long-term modality effect was unreliable when serial recall was tested. Gardiner, Gregg, and Gardiner (1984) found a large long-term modality effect with backward recall, but Madigan (1971) found no modality effect with backward recall in the immediate recall task. Finally, although a suffix effect is found in the through-list distractor task (Glenberg, 1984), the effect differs somewhat from the suffix effect found in immediate recall (Huang \& Glenberg, 1986).

Based on the somewhat limited evidence presently available regarding the long-term modality effect, the tentative conclusion is that it reflects different mechanisms from the modality effect in immediate recall. However, it is unlikely that the two effects are completely unrelated, or that the finding of auditory superiority in two rather different situations is coincidental. What is more likely is that both modality effects reflect properties of the auditory processing stream that differ from those of the visual processing stream. Which property of the auditory stream underlies the long-term effect is not clear at this point, but Glenberg and Swanson (1986) have proposed that the critical property is the finer encoding of temporal information in the auditory modality as opposed to the visual. (See also Gardiner, 1983, for a similar argument.) Given that temporal information (in the form of associations between successive items) is important in the auditory modality, Glenberg's temporal distinctiveness hypothesis is one account of the long-term modality effect that can probably be integrated into the separate-streams model.

In connection with Gardiner and Gregg's (1979) longterm modality effect, it should be noted that a number of modality effects are now appearing in long-term memory tasks. These long-term modality effects are not always manifested as an auditory superiority for recent items; instead, one sees complex interactions between presentation modality and various experimental manipulations. For example, Anderson (1986) reported a generation effect with visual presentation of clichés but not with auditory presentation. Nilsson (1979, Experiment 2) required subjects to remember, from a list of 15 words, either 5 words that began with a certain letter or 5 words that rhymed with a specified word. Type of task was orthogonally combined with presentation modality. For the letter task, visual presentation produced higher recall, but for the rhyme task, auditory presentation was better.
In a study by Peca, Reid, and Mason (1982), subjects either counted the $e s$ in each word or rated the words on an active-passive dimension during study. For the rating task, visual presentation produced higher recognition scores than did auditory presentation; for the lettercounting task, the modality effect was reversed. I have found a similar interaction (Penney, 1986). In one encoding condition, subjects were asked to count the number of consonants in each word during list presentation. On a subsequent frequency judgment test, higher mean judgments were given if presentation had been auditory rather than visual. When the subjects were asked about the sound of items during the study phase, higher frequency judgments were given for visually than for auditorily presented items.

In connection with long-term modality effects, several other reports must be mentioned. Conway and Gathercole (1987; Gathercole \& Conway, 1988) reported better longterm retention when there was acoustic input during the study phase, but the auditory advantage extended throughout the list of 30 items rather than being confined to the terminal item. A final long-term modality effect that must be mentioned is that found in studies of priming. Kirsner and Dunn (1985) have summarized a number of experiments demonstrating reduced repetition priming when presentation modality was changed from the first to the second presentation.

Given the preliminary nature of the work on long-term modality effects, it is premature to attempt any theoretical account at this point. Nevertheless, one can be sure that an explanation only in terms of an auditory sensory store will not suffice. (But see Engle \& Mobley, 1976, for a long-term modality effect that is compatible with a sensory-stores hypothesis.) The separate-streams model may, on the other hand, offer some direction. If the longterm memory trace is a record of the input processing, as Kolers and Roediger (1984) and Kirsner and Dunn (1985) have suggested, there should be strong interactions between presentation modality and the nature of the processing required at encoding. Modality effects should be obtained when encoding tasks tap processing mechanisms that differ for audition and vision and the retention test is sensitive to these differences. The explanation of modality effects in long-term memory, like the account of short-term memory modality effects, will be found in the different capabilities and properties of the auditory and visual processing streams. Thus the understanding of modality effects is central not only to an understanding of short-term memory but also for a complete account of long-term memory as well.

Another modality effect that cannot be accommodated within the PAS model was reported by Hopkins, Edwards, and Cook (1973). They used the Brown-Peterson distractor task and found not only modality-specific interference, but also an interaction between presentation modality and distractor modality in the release from proactive interference. Whereas the modality effect observed in the BrownPeterson task and the interaction between stimulus and 
distractor modalities can be accommodated within the framework of a long-lived, large-capacity echoic memory store, the explanation of the release from PI is not clear. In contrast, the separate-streams hypothesis offers an account of both effects. The modality-specific interference occurs when both distractor and memory items require processing within the same stream. The processing mechanisms become overloaded and interference is observed. If memory and distractor items are in different modalities, different processing mechanisms are used, and the load on one modality is reduced.

The explanation of the release from PI is more complicated. An auditory memory item will be represented in both the A and P codes; a visual item will be represented in both the $\mathrm{P}$ code and the visually based code. Auditory distractors will impair retention of the $A$ and $P$ codes but not the visual code. With auditory distraction, changing from auditory to visual presentation of the memory items results in a new type of code (the visually based code) on the postshift trial, and a concomitant release from PI. Changing from visual to auditory presentation means a loss of the visual code, but no new encoding dimension is introduced, because the A code is effectively disrupted by the auditory distractor. There is therefore no release from PI.

When the distractor material is presented visually, the situation is reversed. The visual distraction impairs retention of the visual code, but has little effect on the A and $P$ codes. Changing from visual to auditory presentation means that the subject has a richer and more complete representation of the items (in the A code) after the shift. Hence the release from PI. Changing from auditory to visual presentation means that the subject loses the benefits of the A code and must rely on the $P$ code. There is no new coding dimension, because the visual interference effectively eliminates the visual code. With no new coding dimension and no improvement in the memory representation, there is nothing to lead to improved performance or a release from PI.

In summary, the first criticism of the PAS model is that it underestimated both the number of items that were represented in the "echo" and the length of time that information persisted. If one enlarges the hypothesized capacity of the PAS from one or two items to six or seven, and if one further assumes that echoic information can survive in silence for periods of up to $60 \mathrm{sec}$, then this type of sensory-stores hypothesis offers a reasonable account of the auditory superiority in short-term memory tasks, the auditory suffix effect, and the effects of auditory and visual distractor tasks. Because of its explanatory power, I have incorporated the sensory-stores hypotheses into the separate-streams model as the A code. However, that is only a small part of the total picture. The real criticism of the PAS model, or of any sensory-stores model, is that there are too many other modality effects that the model simply does not fit.

\section{The Translation Hypothesis}

One hypothesis intended to account for the original modality effect was that visually presented information had to be converted to a verbal form for rehearsal (Laughery \& Pinkus, 1966; Sperling, 1963, 1967). The translation required time, giving the auditorily presented items an advantage. The translation hypothesis has not received much attention lately, probably because it is unable to account for many aspects of the modality effect. Furthermore, it was never intended to explain suffix effects. Nevertheless, it now seems that conversion of visually presented verbal input into a phonological code through silent articulation is an important memory process that must be taken into consideration. However, the goal here is to show that the translation hypothesis is not an adequate account of modality effects.

First, the translation hypothesis predicts that the modality effect will disappear or be substantially reduced if the presentation rate is slow enough. If visual items are presented slowly, there should be sufficient time for the translation process to be completed and the items adequately rehearsed. Laughery and Pinkus (1966) did find that the modality effect disappeared at the slower presentation rates. Unfortunately, they did not report serial position curves, so that an interaction between presentation modality and serial position may have been hidden. On the other hand, several investigators have reported a modality effect that is reduced at the slower presentation rate, but does not disappear. The most convincing data is that of W. A. Roberts (1972), who found a modality effect for recall from primary memory with presentation rates as slow as 4 and $8 \mathrm{sec}$ per item. Provision of extra time during list presentation for the translation of visual input to occur is not sufficient to overcome the modality effect.

A second prediction based on the translation hypothesis that is not borne out is that the auditory superiority should persist beyond the recency part of the serial position curve. The translation hypothesis attributes the modality effect to an encoding deficit such that the encoding of visual stimuli is not as rapid or efficient as that for auditory stimuli. If so, conditions that produce a large modality effect on the recency list item should produce an equal effect on prerecency items. Such is not the case (Murdock \& Walker, 1969; W. A. Roberts, 1972). Some investigators have even found evidence of a small visual superiority for primacy items in free recall (e.g., Craik, 1969; Engle, 1974; Murdock \& Walker, 1969).

Evidence against the translation hypothesis as an account of the modality effect comes from the work on the effects of silent articulation compared to articulation with auditory feedback. The translation hypothesis predicts that silent articulation and overt articulation with the sound of the subject's voice masked by noise should both produce the same beneficial effect on recall as does overt vocalization. It is clear that vocalization with concurrent auditory feedback has a beneficial effect on recall of 
several very recent items, and that this effect is similar to the original modality effect. In contrast, when the auditory feedback is absent, the beneficial effects of articulation are not to be found, and there is even some evidence that articulation is detrimental.

First, consider the effects of vocalization with auditory feedback. Vocalization of a list of visually presented items has improved recall of the last few list items in serial recall (Conrad \& Hull, 1968; Crowder, 1970, 1986; Gathercole, Gardiner, \& Gregg, 1982; Greene \& Crowder, 1984; Kappel, Harford, Burns, \& Anderson, 1973; Murray, 1966; Nairne \& Walters, 1983; Routh, 1970). For early list items, however, the vocalization sometimes reduces recall relative to a condition in which the experimenter reads the item aloud while the subject reads them silently (Arenberg, 1976; Crowder, 1970, 1986; Greene $\&$ Crowder, 1984), or relative to an auditory presentation condition with no concurrent visual presentation (Gathercole et al., 1982). Engle and Roberts (1982) also found a beneficial effect of vocalization on recall of the last few list items in free recall, and Tell and Ferguson (1974) reported an interaction between retention interval and vocalization condition in the Brown-Peterson distractor task. Tell and Ferguson found that for the shortest retention intervals, vocalization by subject or experimenter produced higher recall than did silent reading, but at the longer retention intervals, subject vocalization resulted in much lower recall than did experimenter vocalization.

Silent articulation (mouthing) or vocalization under conditions that eliminate auditory feedback does not improve recall, as the translation hypothesis would suggest, but in fact actually impairs recall. When subjects were instructed to articulate visually presented stimuli visibly but silently, recall of primacy items was lower than for either silently read or overtly vocalized lists (Greene \& Crowder, 1984, 1986; Nairne \& Walters, 1983). For recency items, mouthing sometimes produced higher recall than silent reading (Green \& Crowder, 1986; Nairne \& Walters, 1983), but it never resulted in recall as high as when the subjects vocalized audibly. Further evidence that the auditory feedback is critical and not feedback from the articulatory activity was provided by Murray (1965), who found that the beneficial effects of vocalization were reduced if the subject's voice was masked by white noise. Crowder (1986) also reported that white noise reduced recall when subjects whispered visually presented words during their presentation. In this case, the noise was loud enough to mask the sound produced by the subjects. When auditory presentation is used and vocalization does not introduce new acoustic information, it is detrimental to recall (Mackworth 1964, Experiment 4).

Further evidence that articulation without auditory feedback does not have the same effects as articulation with feedback was presented by Gathercole (1986) and by Turner et al. (1987). Gathercole found that postlist distractor activity involving silent articulation did not reduce the modality effect, but that distractor activity involving audible speech did. Turner et al. investigated recency and suffix effects in lists that were read silently, mouthed, or read aloud. Based on their findings that recency and suffix effects reacted differently to various experimental variables, depending on whether the lists had been mouthed or read aloud, they concluded that recency and suffix effects found with mouthed lists did not reflect the same underlying mechanisms as did these effects with lists that had been heard. It is clear that silent articulation and articulation with auditory feedback do not have the same effect.

Vocalization during the study phase seems to have two different effects. First, there is a beneficial effect similar to the effect of auditory presentation. The sound of the subject's own voice provides auditory input that leads to storage of information in the A code, the beneficial effects of which are apparent for the last few items in the list. The second effect of vocalization is negative: Articulation in the absence of auditory input is a source of interference, and it reduces recall of nonrecency items. The mechanism is not clear, but it may well be that attention to the articulatory activity preempts a more effective type of rehearsal (Kellas, McCauley, \& McFarland, 1975). In terms of the translation hypothesis, silent articulation may produce an "auditory" code, but the code so produced (the P code) is clearly not the same code as that produced as a result of perceptual analysis of auditory input (the A code).

Although the translation hypothesis does not provide an explanation of modality effects, there is evidence (see Baddeley, 1986) that visually presented verbal items are translated into a phonological code that plays an important role in retention. As evidence for the importance of the articulatory process, Baddeley $(1983,1986)$ cited four empirical phenomena: the phonological similarity effect, the word-length effect, the unattended-speech effect, and the effects of articulatory suppression. The phonological similarity effect refers to the finding that immediate serial recall of consonants is lower when consonants have names that rhyme than when the names are not similar in sound (see Conrad, Baddeley, \& Hull, 1966; Conrad \& Hull, 1964). The word-length effect refers to the finding that memory span is a function of the length of time it takes the subject to articulate the target items (Baddeley, Thomson, \& Buchanan, 1975). The unattended-speech effect refers to the interference produced by the presentation of speech during study of a visually presented memory list (Salamé \& Baddeley, 1982). The simultaneous speech impairs retention, even though the subject is instructed to ignore the speech.

Consistent with the distinction I have hypothesized between the A code for auditorily presented items on the one hand, and the P code generated for visual items on the other, there is evidence that presentation modality interacts with phonological similarity, word-length, and articulatory suppression. Articulatory suppression (having the subject articulate an irrelevant sound during study of a memory list) lowers visual memory span but has much less effect when auditory presentation is used (Levy, 
1971). When articulatory suppression is used with visual presentation, the phonological-similarity effect disappears, but that is not the case for auditory presentation (Baddeley, Lewis, \& Vallar, 1984; Peterson \& Johnson, 1971). Similarly, articulatory suppression during list presentation eliminates the word-length effect for visual presentation, but not for auditory (Baddeley et al., 1984).

To account for the phonological-similarity effect, the word-length effect, the unattended-speech effect, and the effects of articulatory suppression, Baddeley $(1983,1986)$ described a subsystem of memory called the articulatory loop, which was composed of two parts-an articulatory rehearsal process involving subvocal speech, and a phonological input store. Auditory presentation provides obligatory access to the phonological store, and a phonological code may be generated for visually presented items through the process of subvocal rehearsal. The wordlength effect reflects the operation of the articulatory rehearsal process, whereas the unattended-speech effect results from the auditory information's gaining access automatically to the phonological store and thereby disrupting the translation of visual input. Phonological similarity reduces recall, because similar, and therefore confusable, traces are laid down for auditorily presented items or silently articulated visual items. The effect of articulatory suppression is to hinder or to prevent the translation of visual items into the phonological code. In the absence of the translation process, there is no basis for the phonemic similarity effect, the word-length effect, or the unattended-speech effect.

Baddeley's hypothesis of the articulatory loop accounts nicely for the empirical phenomena he described, but it does not account for the various modality effects described here. Baddeley's hypothesis implies that auditorily presented items and silently articulated visual items produce the same kind of code in short-term memory, the only modality difference being that the phonological encoding is obligatory for auditory items but not for visual. The literature reviewed in this paper shows clearly that there are differences in the processing of auditory and visual input that Baddeley's articulatory loop does not allow. The modality effects that appear in divided attention tasks and long-term memory tasks, the modality-specific memory deficits, and many other findings simply cannot be accommodated within Baddeley's model.

\section{PROPERTIES OF THE STREAMS AND CODES}

\section{The Auditory Stream and the A Code}

The A code necessarily has as its basis the perceptual analysis of acoustic information. An item must be heard in order for it to be represented in the A code. The studies comparing silent and overt vocalization, or overt vocalization with and without auditory feedback, indicate clearly that auditory feedback has very large effects on retention. Imagining the sound of visually presented items does not create the same representation as does hearing the items (Naime \& Pusen, 1984, Experiment 3). Nairne and Pusen presented lists visually with the first few items accompanied by auditory presentation. In one condition, subjects were instructed to imagine the sound of the speaker's voice saying the last three items, which were presented in the visual mode only. Recall of these three items was actually higher in the control condition, in which subjects were told to encode the items in their own inner voice, than it was in the "imagine" condition. Nairne and Pusen also found that when subjects were instructed to imagine the sound of a visually presented suffix, there was no suffix effect at all. Similarly, Nairne and Crowder (1982, Experiment 2) found that a silently mouthed suffix did not impair recall of a vocalized list as much as did a vocalized suffix. Manning (1987) found similar results with an auditorily presented list, provided that subjects did not have to attend to the suffix. In order to interfere maximally, the suffix must actually be heard. It seems that an internally generated auditory or phonological code does not have the same properties as the sensory-based code.

Both the capacity and the durability of the A code differ markedly from the properties hypothesized for Crowder and Morton's PAS. The number of items that can be represented in the A code at the same time appears to be five or more. This estimate is based on the number of serial positions that manifest the modality effect when puremode lists are presented in free recall (Murdock \& Walker, 1969), in serial recall (Murray, 1966), or in a serial probe task (Murdock, 1967). The estimate of five items is also consistent with the number of items at the end of an auditory list more affected by an interpolated auditory distractor task than by an analogous visual task (Gathercole et al., 1983). Experiments producing a modality effect when a silent interval of 20 to $60 \mathrm{sec}$ intervenes between list presentation and recall indicate that the echoic information must last as long as this (e.g., Engle \& Roberts, 1982; O. C. Watkins \& M. J. Watkins, 1980). Similarly, the finding of a suffix effect when the suffix is delayed by $20 \mathrm{sec}$ (M. J. Watkins \& Todres, 1980) is also consistent with a very long-lasting echo.

A salient property of the auditory stream is the existence of strong associations between items that are presented sequentially. The A code seems to be specialized to preserve the order of items in short-term memory. In a memory span task, M. J. Watkins and Peynircioglu (1983) found that changing the output order from serial to alphabetic or numeric had a greater adverse effect on recall of auditory letters as opposed to visual letters. Madigan (1971) found no modality effect with backward serial recall (but in a more recent study, Mayes, 1988, did obtain a modality effect with backward recall in a running memory span task.) The requirement of a temporal output order is compatible with the auditory modality; in contrast, the visual modality is more flexible when a different output order is required. When recall order is not constrained, as in free recall, there is evidence that subjects preferentially adopt a forward report order for auditory but not visually presented items (McFarland \& Kellas, 1974; Nilsson, Wright, \& Murdock, 1975, 1979). 
A forward report order is consistent with the existence of strong unidirectional associations between auditory items.

Broadbent, Cooper, Frankish, and Broadbent (1980) also reported an interaction between report order and presentation modality. In one condition (forward report order), lists of nine digits, represented as three groups of three, were reported in the order of presentation. In the second condition (backward report order), the subjects reported the last group of digits first and then the first and second groups. For visual presentation, a difference favoring the backward order was found for the first and last groups reported. A different pattern of results was obtained after auditory presentation. For the first group of digits reported, backward recall was slightly higher than forward, but for the second and third groups, the forward recall was better. Metcalfe and Sharpe (1985) also found a reduced modality effect when subjects recalled groups of items in the reverse order of presentation. Like the M. J. Watkins and Peynircioglu (1983) experiment, the studies by Broadbent et al. (1980) and by Metcalfe and Sharpe (1985) show that changing the report order from strict serial recall to something else is more detrimental for recall of auditory items than it is for recall of visual items.

The postulation of sequential associations in auditory short-term memory accounts for the ear-by-ear report of dichotic stimuli, while at the same time it is consistent with the fact that meaning or stimulus class can override organization according to ear of arrival (Gray \& Wedderburn, 1960; Yntema \& Trask, 1963). Even when there is nothing to distinguish two simultaneous items, so that a subject has no basis for defining different channels, a sequential recall order predominates (Parkinson, Knight, DeMaio, \& Connors, 1974; Savin, 1967). Even stronger evidence indicating the strength of the temporal organization of auditory items was presented by Bryden (1964) and by Whitmore (1972). In these experiments, a basis for semantic organization was introduced that would encourage the subjects to recall according to temporal pairs rather than in the ear-by-ear order. Even under these conditions, there was still a preference, albeit a weakened one, for a sequential report order.

My own work has provided evidence for the strength of the auditory sequential associations as well. The sequential report order is found when four-channel presentation of stimuli is used (two auditory and two visual items all presented simultaneously). When subjects free recall items from only one modality, the sequential report order was found to predominate for auditory items, but the temporal pairs order was preferred for the visual items (Penney, 1974a, 1974b). When recall was probed by another item that had been presented either at the same time or in the same channel (that is, at the same place) as the target, presentation modality was found to interact with probe type. For visual items, the same-time probe was slightly better, but for auditory items, the same-channel probe was better (Penney, 1974a). In a dichotic listening task, sub- jects were far better at identifying two probe items as having the same order as in the study list, or the reverse order, than they were at identifying two probe items as having been presented simultaneously (Penney, 1976). It seems that auditory items are organized in short-term memory according to time of arrival, such that the order of successive items is well preserved. Two simultaneous auditory items are treated as being totally unrelated and appear to be stored as if there were no associations between them.

Whether there are direct associations between successive items, as I have hypothesized, or whether the temporal organization of the auditory mode can be conceptualized better in some other way is a question that should be raised. For example, Metcalfe and Sharpe (1985) presented evidence that access to higher chunks is more important than item-to-item associations. In their experiment, recall of chunks in backward order virtually eliminated the auditory superiority, but reordering items within a chunk for output left the modality effect undisturbed. Glenberg and Swanson (1986) have proposed a temporal distinctiveness explanation of the long-term modality effect, whereby temporal context is more finely encoded in the auditory mode than in the visual. Both of these alternatives are so recent that there has been no work done to test them against the sequential associations hypothesis. Nevertheless, one thing is clear: The strength of temporal organization is one dimension along which the auditory and visual modalities differ.

There is evidence to support the hypothesis that auditorily presented items have "automatic" access to the A code-that is, that this code is generated and stored for auditory items even when the subject makes no attempt to maintain it. On the basis of the finding that unattended speech reduced recall of visually presented digits, Salamé and Baddeley (1982) concluded that unattended speech has automatic access to the phonological code. When subjects vocalized an irrelevant word repeatedly during presentation of the digits and therefore could not generate the phonological code for visual stimuli, the effect of irrelevant speech disappeared. Salamé and Baddeley concluded that unattended speech and silent articulation feed into the same system (the phonological store), and that the automatic access of the auditory stimuli to the phonological store disrupted the generation or storage of the phonological code for visual stimuli.

Further evidence for the hypothesis of automatic access comes from studies of the suffix effect and of dichotic listening. The suffix effect can be regarded as reflecting a failure of selective attention, in that the subject cannot suppress processing of the suffix. A number of experiments have shown that when stimuli are presented dichotically, and when the subject is instructed to focus on one message and ignore the other, there is considerable semantic processing of the unattended message (e.g., Corteen \& Wood, 1972; Norman, 1969; Treisman, 1960, 1964).

There is evidence that maintenance of the A code does not require active attention. Subjects I have tested in bi- 
sensory tasks often report adopting a strategy of attending to the visual stimuli and ignoring the auditory stimuli, because the latter can be remembered anyway. Anderson and Craik (1974) presented evidence that visual items require attention in order to be maintained in short-term memory, whereas auditory items could be retained in an echoic store without continued attention. They required subjects to perform a choice reaction time task during list presentation, in which the stimuli in the reaction time tasks were lights when the memory items were presented auditorily, and tones when the memory items were presented visually. For primary memory items only, the visual ones were affected by the concurrent task but there was no decrement for the auditory items. (For the secondary memory component, both modalities were affected.)

A second piece of evidence pertaining to the relatively effortless maintenance of the echo comes from studies of short-term memory in the elderly. Several experiments have shown a lesser decline with age for auditorily presented memory items than for visual (Arenberg, 1968; McGhie, Chapman, \& Lawson 1965; Taub, 1972). Elderly people are hypothesized to show greater deficits in tasks requiring more effortful processing, and lesser deficits when the processing required is more automatic. To the degree that retention of auditory items relies on the echo that does not require effort for maintenance, we would expect performance on auditory memory tasks to decline less rapidly with age, relative to performance on similar visual tasks.

In summary, three properties of the auditory stream have been identified. First, there is a large capacity for storing sensory information. This sensory information persists for periods of up to a minute in the absence of subsequent auditory input. Persistence of the auditory sensory information (the A code) underlies the original modality effect and is often called echoic memory. The echo does not decay; rather, it is highly susceptible to interference from subsequent auditory input-hence the suffix effect, and the large effect upon recency items of any distractor task that involves subjects' hearing or saying stimuli. The echo is hypothesized to preserve associations between successive items. This second property underlies the ear-by-ear report found in dichotic listening, the preference for a forward report order of auditory items and the reduction or loss of the modality effect when a different report order must be used, and Penney and Butt's (1986) finding that for auditory targets, a temporally distant auditory probe was more effective than a temporally adjacent visual probe. The third property of the auditory stream is the automatic generation and maintenance of the A code.

\section{Studies on Lip-Read Stimuli}

Recently, a number of experiments have appeared to show that lip-read and auditory stimuli have similar memory codes. The general finding is that auditory and lip-read suffixes both produce interference with recall of auditory and lip-read lists. If the "echo" is purely acous- tic, a silent lip-read suffix should not produce an impairment. Equally, if a lip-read list is stored in a code that contains no acoustic components, one would not expect interference from an auditorily presented suffix. Although the existing data on this matter suggest some overlap or similarity in the memory codes for lip-read and heard stimuli, the data do not justify the conclusion of identical memory codes.

Spoehr and Corin (1978) presented lists auditorily and followed the lists by no suffix, a spoken suffix (with the speaker's lips hidden from the subject), a lip-read suffix with no sound heard, a lip-read suffix with accompanying sound, or a suffix presented on a card. The graph they presented shows that the auditory suffix, the silent lipread suffix, and the lip-read suffix accompanied by sound produced identical effects, and all produced more errors than were found for the no-suffix control or the suffix presented on a card. However, caution must be observed in interpreting their results. In particular, one cannot conclude that the lip-read suffix produced the same effects as did the spoken suffix. Spoehr and Corin normalized their data, so that the dependent variable was the percentage of total errors made that occurred at each serial position. Spoehr and Corin did not present the actual mean number of errors made in each condition, so the reader cannot tell whether or not the lip-read suffix actually produced as many errors in total as did the spoken suffix. All that can be concluded from their data is that the distribution of recall errors across serial positions was the same for the lip-read and for the spoken suffix, and that this pattern of errors differed from that found in the nosuffix and card-suffix conditions.

Campbell and Dodd (1980) presented digits visually by using a digit display device or by showing a videotape of someone saying the lists with the sound on the videotape turned off. Either no suffix followed the list or a suffix was heard, but there was no visible lip movement. The auditory suffix impaired recall of both lip-read and graphic lists, but the patterns of interference differed. For the lip-read lists, the effect of the suffix was greater for items near the end of the list; for the graphic lists, the effect seemed to be distributed more or less equally throughout the list. Campbell and Dodd (1982) compared the effects of silent lip-read and heard suffixes and found that the lip-read suffix produced a lot of interference on all list items. In contrast, the heard suffix reduced recall of only the terminal list item, and even then had a smaller effect than the lip-read suffix did.

Campbell and Dodd (1980) tested subjects' recall of spoken lists and found it to be much higher than recall of lip-read lists. If one can accept Campbell and Dodd's claim that the lipreading task did not present discrimination problems for subjects, the finding of better recall for auditorily presented lists than for lip-read lists indicates clearly that the memory codes for the two modalities are not identical. The richness and durability hypothesized to characterize the A code was manifested in high recall of the auditory lists. In comparison, the lower recall of 
the lip-read lists suggests a relatively impoverished memory code.

Experiments demonstrating that a lip-read suffix impairs retention of an auditorily presented list were performed by Gardiner, Gathercole, and Gregg (1983), Greene and Crowder (1984, Experiment 3), and Manning (1987). Greene and Crowder compared the effects of suffixes that were either lip-read only or both lip-read and heard on recall of lists that were either lip-read only or both lip-read and heard. With the exception of the terminal list item, the effects of the two suffixes were virtually identical. For the terminal item only, there was a small interaction between list and suffix modality such that when both were the same, the amount of interference was slightly greater.

Gardiner et al. (1983) compared the effects of graphic and lip-read distractor items upon recall of word lists presented auditorily or visually (graphically). Lip-read distractors reduced recall of recency items in vocally presented lists much as an auditory distractor task is known to do (cf. Broadbent et al., 1978; Gathercole et al., 1983). The lip-read distractor had a much smaller effect on recall of the graphically presented lists.

At first glance, it would appear that the results of the experiments by Gardiner et al. (1983) and by Greene and Crowder (1984) indicate that the encoding of lip-read stimuli is the same as that for auditorily presented stimuli. However, in these experiments, the direct comparison between the effects of lip-read and heard suffixes on recall of auditorily presented lists was not made. Manning (1987) did compare several different types of suffixes on recall of auditory lists, and her results indicate that the effects of lip-read and auditory suffixes are not the same. When subjects could ignore the suffix, the lip-read suffix did not produce nearly as much interference as a heard suffix did; only when the subjects had to articulate the lip-read suffix before recalling the memory items were the effects of the lip-read suffix similar in magnitude to those of a heard suffix.

There is one further study that seems to suggest some degree of commonality in the memory codes for auditory and lip-read items. Dodd and Campbell (1984, Experiment 2) presented lists that contained a mixture of auditory and lip-read items or a mixture of auditory and graphic items. After each list, subjects were instructed to recall items from one modality. Dodd and Campbell found that subjects were far more likely to report words from the uncued modality for lists containing both auditory and lip-read words than for lists containing auditory and graphic lists. In other words, it was more difficult to discriminate between lip-read and auditory items than between graphic and auditory items. However, subjects were able to make the discrimination between lip-read and auditory items to some degree, as is shown by the finding that they made an average of only 23 errors out of a possible maximum of 80 .

To the question of memory codes produced by lip-read and heard stimuli, a recent paper by Campbell, Garwood, and Rosen (1988) offers a possible answer. With lip-read lists, Campbell et al. found that similar effects were produced by lip-read suffixes, suffixes that were lip-read and heard, and lip-read suffixes that were accompanied by a pulse train indicating the pitch of speech. When the lip-read list items were accompanied by the auditory pulse train, the different types of suffixes produced different effects. The addition of a pure tone to the pulse train virtually eliminated the recency effect and did eliminate all suffix effects, a phenomenon that does not occur with auditory lists (Routh \& Lifschutz, 1975).

In conclusion, it appears that although the memory codes for lip-read and auditory stimuli are closely related and very similar, they are not identical. Campbell et al. (1988) proposed that both lipreading and auditory presentation give rise to a phonetic code, but that the phonetic representation is underspecified for lip-read stimuli. This phonetic code is hypothesized to give rise to both suffix and recency effects. The phonetic code proposed by Campbell et al. is not the same as the phonological code proposed by Baddeley, nor is it the same as the A code proposed here. Whether this third code will be required as an explanatory construct in addition to the A code, or whether it will replace the A code, is not known at the present time.

\section{The Visual Stream}

The first obvious difference between the auditory and visual streams is that the visual has a stronger spatial component and a relatively weaker temporal one than does the auditory stream. The dominant organization within the auditory modality is temporal with sequential associations being evident; in the visual mode, it seems that items presented simultaneously in different spatial locations are strongly associated. There is really no appropriate spatial analogy in the auditory modality, because simultaneous auditory presentation introduces both perceptual and memory problems. For example, in dichotic split-span tasks, it is difficult for people to remember six digits, whereas this is easier with either bisensory presentation or purely sequential presentation in one modality. To make presentation parameters as similar as possible for auditory and visual presentation, and to control study time for individual items, investigators have used sequential presentation of visual stimuli. Instead of regretting the lack of congruity between auditory and visual modes, investigators should view it as a fundamental difference between the two modalities that deserves investigation and recognition in theories of memory.

In contrast to the auditory modality, in which simultaneous (e.g., dichotic) presentation makes the memory task much harder, there is evidence that in the visual mode, simultaneous presentation actually improves serial recall. Broadbent (1956) compared successive and simultaneous visual presentation of six digits with total presentation time held constant, and found higher recall after simultaneous presentation. Mackworth (1962) found the benefit of simultaneous presentation to be so large that recall was 
higher with simultaneous than with sequential presentation, even when study time per item in the latter condition was double that in the former. Crowder (1966) and Frick (1985) have also compared sequential and simultaneous presentation and found that for the same total study time, recall was much higher after simultaneous than after sequential presentation.

In tasks other than serial recall, the benefits of simultaneous visual presentation are apparent as well. Using the Peterson distractor task, Marcer (1967) and Parkinson (1972) found simultaneous visual presentation of the three letters of a trigram to give better recall than either auditory presentation or sequential visual presentation. Snodgrass and Antone (1974) found that simultaneous presentation produced better performance than sequential presentation did, when the subjects were tested on recognition of the order of items within a pair. In a free recall task, Johansson and Nilsson (1979) found that simultaneous visual presentation produced consistently higher recall of meaningful sentences than did sequential presentation. The experimental literature leaves no doubt that recall of visually presented verbal items is improved by simultaneous presentation. In addition, studies discussed earlier indicate that simultaneous presentation may be a critical factor in producing a visual suffix effect. Yet, in spite of the size of these effects, existing theories of short-term memory do not take them into account.

There is evidence that grouping or chunking may operate on different bases in the auditory and visual modalities. Temporal grouping has been shown to be highly effective in promoting chunking and increasing recall of auditorily presented lists (Ryan, 1969a, 1969b), but Frankish (1985) has shown that temporal grouping does not have as much effect when presentation is visual. However, there is evidence that certain spatial arrangements facilitate chunking and recall of visual items, relative to ungrouped presentations (Kahneman \& Henik, 1977; Mayzner \& Adler, 1965; Mayzner \& Gabriel, 1963, 1964).

In contrast to the ear-by-ear or sequential report order found in the auditory modality, two simultaneous items presented in the visual mode tend to be recalled together (Penney, 1974b; Sampson \& Spong, 1961; Schurman, Everson, \& Rollins, 1972). Rollins, Schurman, Evans, and Knoph (1975) had subjects practice both sequential and temporal pairs recall orders for either three auditory pairs or three visual pairs. They found that even after a practice session of 120 trials on each report order, the interaction between recall order and presentation modality did not disappear. After visual presentation, recall was better when subjects reported simultaneous items together; after auditory presentation, higher recall was obtained when subjects adopted a sequential report order. Rollins et al. (1975) found that informing subjects either before or after list presentation what the required recall order would be made little difference in the level of recall. They concluded that "subjects have little control over the order in which simultaneous digits are processed. Rather, this type of information is processed automatically and differently by the two modality systems"' (p. 180).

A study by Metcalfe, Glavanov, and Murdock (1981) examined the interaction between presentation modality and recall order based on spatial or temporal location. Lists of 9 or 12 words were presented either auditorily or visually, in chunks of three items. Within a chunk, spatial location (left, center, or right) was not correlated with temporal position. The subjects were given grids on which to recall the items, with the subjects in the spatial and temporal recall conditions given different instructions. In the temporal condition, the subjects reported the first word presented in a chunk in the left-hand box, the second word in the middle box, and the third word in the right-hand box. The spatial locations of the words were to be ignored. In the spatial recall condition, the subjects reproduced the spatial locations of the items and ignored the temporal positions. In three experiments, Metcalfe et al. found a crossover interaction between presentation modality and recall order. With the temporal report order, auditory presentation led to higher recall than visual presentation did; with the spatial report order, visual presentation led to higher recall.

O'Connor and Hermelin (1978) have extensively studied the question of spatial and temporal information in the auditory and visual modalities and have come to conclusions somewhat similar to the ideas presented in this paper. Several of their experimental findings offer support for the hypothesis presented here that spatial information plays an important role in visual memory. In addition, their results are particularly informative in indicating the conditions under which spatial information is overshadowed by temporal information. O'Connor and Hermelin (1972) presented sequences of three successive digits in a spatial array such that temporal and spatial positions were not correlated. Subjects were asked to report the "middle digit." When presentation was auditory, both normal and blind subjects reported the second digit presented. In contrast, when presentation was visual, both deaf and hearing subjects reported the digit that had occupied the middle spatial location. Apparently the children tested in this experiment did not perceive any ambiguity in the instructions, for only two out of 80 asked "which" middle digit was to be reported.

However, other work by O'Connor and Hermelin (1973) suggests that when normal subjects are asked to remember visually presented items, they tend to report them according to the temporal order, not the spatial arrangement. In contrast, deaf children preferred to report the spatial order. In another experiment in the same paper, O'Connor and Hermelin used a recognition matching task. Whereas deaf children were more likely to match the spatial arrangement, hearing children showed a strong preference for matching the temporal order of the digits. These results are consistent with the hypothesis that hearing children retain the items by means of the $P$ code, which is sequentially organized, and not by means of a visually based code. Deaf children are probably less able to use 
a $P$ representation effectively, and they are more likely to rely on a visual code in which the spatial components are more salient.

If subjects with normal hearing tend to rely on the $P$ code for retention of visually presented verbal stimuli, the difficulty experienced by a number of investigators in demonstrating the effect of spatial factors can be explained. Murdock (1969) attempted to overcome the auditory superiority in immediate recall by testing spatial rather than temporal information (e.g., by giving a spatial position or the spatially adjacent item as a probe). He was unsuccessful; the auditorily presented items were recalled at a higher level than were the visual items. Similarly, Hitch (1974) found that for visually presented items, spatial probes were less effective than temporal association probes. Hitch and Morton (1975) reported that the provision of spatial information redundant with temporal order did not improve retention. The importance of spatial information in recall of visually presented verbal material may not emerge when subjects base their recall on the $\mathrm{P}$ code.

In summary, in contrast to the auditory modality, in which the "echo" persists for a lengthy period of time, there is little evidence for a sensory-based visual code that contributes substantially to performance in typical shortterm memory tasks. Instead, it seems that subjects generate a phonological or $\mathrm{P}$ code, which allows for rehearsal, and that performance is based mainly on this phonological code. Evidence for a visual code is found when experimental conditions prevent the formation or maintenance of the $P$ code so that subjects must rely on the visual code. Unlike the "echo," which appears not to require continued attention for maintenance, the $P$ code does require effort. In the auditory modality, strong associations occur between successive items; in contrast, in the visual modality, simultaneously presented items are strongly associated. Associations between successive items can be formed, probably through the use of the P code and subvocal rehearsal, but the associations are not as strong as the sequential associations between successive auditory items. Relative to sequential presentation of visual items, simultaneous presentation improves recall; this contrasts with the disruptive effect of simultaneous presentation in the auditory modality as evidenced by the difficulty of recalling three dichotically presented digit pairs. Visual interference effects can be demonstrated more easily with simultaneous presentation of visual stimuli than with sequential presentation.

\section{FINAL WORDS}

As recently as 1986 , Crowder stated, "the classical auditory visual modality effect is large and reliable, but still poorly understood" (p. 268). I disagree with the last part of Crowder's statement. My goal in presenting the separate-streams model has been to summarize and integrate the existing literature on modality effects and to outline a model of the human memory system that will ac- count for many of these effects. A model of this type will provide some explanations, but it will undoubtedly raise more questions than it will answer. If the separate-streams model does nothing more than establish the importance of modality effects in the study of memory and encourage the investigation of these effects, then I will consider it to have been a success.

\section{REFERENCES}

Allport, D. A., Antonis, B., \& Reynolds, P. (1972). On the division of attention: A disproof of the single channel hypothesis. Quar terly Journal of Experimental Psychology, 24, 225-235.

Anderson, C. M. B., \& Craik, F. I. M. (1974). The effect of a concurrent task on recall from primary memory. Journal of Verbal Learning \& Verbal Behavior, 13, 107-113.

ANDERSON, R. E. (1986, November). Distinguishing between memories of reading, hearing, and thinking. Paper presented at the annual meeting of the Psychonomic Society, New Orleans.

ARENBERG, D. (1968). Input modality in short-term retention of old and young adults. Journal of Gerontology, 23, 462-465.

ARENBERG, D. (1976). The effect of input condition on free recall in young and old adults. Journal of Gerontology, 31, 551-555.

Baddeley, A. D. (1983). Working memory. Philosophical Transactions of the Royal Society of London, B302, 311-324.

BADDELEY, A. D. (1986). Working memory. Oxford, England: Oxford University Press.

Baddeley, A. D., \& Hull, A. (1979). Prefix and suffix effects: Do they have a common basis? Journal of Verbal Learning \& Verbal Behavior, 18, 129-140.

Baddeley, A. D., Lewis, V., \& Vallar, G. (1984). Exploring the articulatory loop. Quarterly Journal of Experimental Psychology, 36A, 233-252.

Baddeley, A. D., Thomson, N., \& Buchanan, N. (1975). Word length and the structure of short-term memory. Journal of Verbal Learning \& Verbal Behavior, 14, 575-589.

Balota, D. A., \& DUCheK, J. M. (1986). Voice-specific information and the 20-second delayed suffix effect. Journal of Experimental Psychology: Learning, Memory, \& Cognition, 12, 509-516.

Balota, D. A., \& ENGLE, R. W. (1981). Structural and strategic factors in the stimulus suffix effect. Journal of Verbal Learning \& Verbal Behavior, 20, 346-357.

Basso, A., Spinnler, H., Vallar, G., \& Zanobio, E. M. (1982) Left hemisphere damage and selective impairment of auditory verbal short-term memory: A case study. Neuropsychologia, 20, 263-274.

BROADBENT, D. E. (1956). Successive responses to simultaneous stimuli. Quarterly Journal of Experimental Psychology, 8, 145-152.

Broadbent, D., Cooper, P. J., Frankish, C. R., \& Broadbent, M. H. P. (1980). Modality differences in relation to grouping in immediate recall. British Journal of Psychology, 71, 475-485.

BroAdBent, D. E., \& GREGory, M. (1961). On the recall of stimuli presented alternately to two sense-organs. Quarterly Journal of Experimental Psychology, 13, 103-109.

BroadBent, D., Vines, R., \& Broadbent, M. (1978). Recency effects in memory as a function of modality of intervening events. Psychological Research, 40, 5-13.

BRydeN, M. P. (1964). The manipulation of strategies of report in dichotic listening. Canadian Journal of Psychology, 18, 126-138.

CAMPBEll, R., \& DodD, B. (1980). Hearing by eye. Quarterly Journal of Experimental Psychology, 32, 85-99.

CAmprell, R., \& DodD, B. (1982). Some suffix effects on lipread lists. Canadian Journal of Psychology, 36, 508-514.

Campbell, R., Garwood, J., \& Rosen, S. (1988). Adding sound to lipread lists: The effects on serial recall of adding an auditory pulse train and a pure tone to silently lipread lists. Memory \& Cognition, 16, 210-219.

Conrad, R., Baddeley, A. D., \& Hull, A. J. (1966). Rate of presentation and the acoustic similarity effect in short-term memory. Psychonomic Science, 5, 233-234. 
Conrad, R., \&ull, A. J. (1964). Information, acoustic confusion and memory span. British Journal of Psychology, 55, 429-432.

Conrad, R., \& Hull, A. J. (1968). Input modality and the serial position curve in short-term memory. Psychonomic Science, 10, 135-136.

Conway, M. A., \& Gathercole, S. E. (1987). Modality and longterm memory. Journal of Memory \& Language, 26, 341-361.

Corteen, R. S., \& Wood, B. (1972). Autonomic responses to shockassociated words in an unattended channel. Journal of Experimental Psychology, 94, 308-313.

CraIK, F. I. M. (1969). Modality effects in short-term storage. Journal of Verbal Learning \& Verbal Behavior, 8, 658-664.

CrowDER, R. G. (1966). Visual presentation of stimuli in immediate memory. Psychonomic Science, 6, 449-450.

Crowder, R. G. (1967). Prefix effects in immediate memory. Canadian Journal of Psychology, 21, 450-461.

Crowder, R. G. (1970). The role of one's own voice in immediate memory. Cognitive Psychology, 1, 157-178.

CROWDER, R. G. (1971). The sound of vowels and consonants in immediate memory. Journal of Verbal Leaming \& Verbal Behavior, 10. 587-596.

Crowder, R. G. (1978). Mechanisms of auditory backward masking in the stimulus suffix effect. Psychological Review, 85, 502-524.

Crowder, R. G. (1983). The purity of auditory memory. Philosophical Transactions of the Royal Society of London, B302, 251-265.

Crowder, R. G. (1986). Auditory and temporal factors in the modality effect. Journal of Experimental Psychology: Learning, Memory, \& Cognition, 12, 268-278.

Crowder, R. G., Morton, J. (1969). Precategorical Acoustic Storage (PAS). Perception \& Psychophysics, 5, 365-373.

DALLETT, K. M. (1965). "Primary memory": The effects of redundancy upon digit repetition. Psychonomic Science, 3, 237-238.

DARWIN, C. J., \& BADDELEY, A. D. (1974). Acoustic memory and the perception of speech. Cognitive Psychology, 6, 41-60.

DENNIS, I. (1977). Component problems in dichotic listening. Quarterly Journal of Experimental Psychology, 29, 437-450.

DodD, B., \& CAMPBELL, R. (1984). Non-modality specific speech coding: The processing of lip-read information. Australian Journal of Psychology, 36, 171-179.

Eluott, L. A., \& Strawhorn, R. J. (1976). Interference in shortterm memory from vocalization: Aural versus visual modality differences. Journal of Experimental Psychology: Human Learning \& Memory, 2, 705-711.

ENGLE, R. W. (1974). The modality effect: Is precategorical acoustic storage responsible? Journal of Experimental Psychology, 102, 824-829.

Engle, R. W., \& Mobley, L. A. (1976). The modality effect: What happens in long-term memory. Journal of Verbal Learning \& Verbal Behavior, 15, 519-528.

ENGLe, R. W., \& RoberTs, J. S. (1982). How long does the modality effect persist? Bulletin of the Psychonomic Society, 19, 343-346.

Fell, J. C., \& LAugherY, K. R. (1969). Short-term memory: Mode of presentation for alphanumeric information. Human Factors, 11, 401-405.

FRANKISH, C. (1985). Modality-specific grouping effects in short-term memory. Journal of Memory \& Language, 24, 200-209.

Frankish, C., \& TURNER, J. (1984). Delayed suffix effect at very short delays. Journal of Experimental Psychology: Learning, Memory, \& Cognition, 10, 767-777.

FRICK, R. W. (1984). Using both an auditory and a visual short-term store to increase digit span. Memory \& Cognition, 12, 507-514.

FRICK, R. W. (1985). Testing visual short-term memory: Simultaneous versus sequential presentations. Memory \& Cognition, 13, 346-356.

Frick, R. W., DE RoSe, A. (1986a). Attenuating the visual suffix effect with color. Memory \& Cognition, 14, 391-397

Frick, R. W., \& Rose, A. (1986b). The suffix effect and pre-attentive unit-formation in visual short-term memory. Canadian Journal of Psychology, 40, 97-108.

Gardiner, J. M. (1983). On recency and echoic memory. Philosophical Transactions of the Royal Society of London, B302, 267-282.
Gardiner, J. M., Gathercole, S. E., \& GregG, V. H. (1983). Further evidence of interference between lipreading and auditory recency. Journal of Experimental Psychology: Learning, Memory, \& Cognition, 9, 328-333.

Gardiner, J. M., \& GregG, V. H. (1979). When auditory memory is not overwritten. Journal of Verbal Learning \& Verbal Behavior, 18 705-720.

Gardiner, J. M., GregG, V. H., \& Gardiner, M. M. (1984). Concerning additional evidence of an auditory advantage in prerecency as well as recency recall. American Journal of Psychology, 97, 593-604.

Gardiner, J. M., Thompson, C. P., \& Maskarinec, A. S. (1974). Negative recency in initial free recall. Journal of Experimental Psychology, 103, 71-78.

GatherCole, S. E. (1986). The modality effect and articulation. Quarterly Journal of Experimental Psychology, 38A, 461-474.

Gathercole, S. E., \& Conway, M. A. (1988). Exploring long-term modality effects: Vocalization leads to best retention. Memory \& $\mathrm{Cog}$ nition, 16, 110-119.

Gathercole, S. E., Gardiner, J. M., Gregg, V. H. (1982). Modality and phonological similarity effects in serial recall: Does one's own voice play a role? Memory \& Cognition, 10, 176-180.

Gathercole, S. E., GregG, V. H., \& Gardiner, J. M. (1983). Influences of delayed distraction on the modality effect in free recall. British Journal of Psychology, 74, 223-232.

GLENBERG, A. M. (1984). A retrieval account of the long-term modality effect. Journal of Experimental Psychology: Learning, Memory, \& Cognition, 10, 16-31.

Glenberg, A. M., Swanson, N. G. (1986). A temporal distinctiveness theory of recency and modality effects. Jourmal of Experimental Psychology: Learning, Memory, \& Cognition, 12, 3-15.

Gray, J. A., \& WEDDERBURN, A. A. I. (1960). Grouping strategies with simultaneous stimuli. Quarterly Joumal of Experimental Psychology, 12, 180-184.

GREENE, R. L. (1985). Constraints on the long-term modality effect. Journal of Memory \& Language, 24, 526-541.

Greene, R. L., \& Crowder, R. G. (1984). Modality and suffix effects in the absence of auditory stimulation. Joumal of Verbal Leaming \& Verbal Behavior, 23, 371-382.

Greene, R. L., \& Crowder, R. G. (1986). Recency effects in delayed recall of mouthed stimuli. Memory \& Cognition, 14, 355-360.

Greene, R. L., \& Samuel, A. G. (1986). Recency and suffix effects in serial recall of musical stimuli. Journal of Experimental Psychol ogy: Learning. Memory, \& Cognition, 12, 517-524.

GregG, G. H., \& Gardiner, J. M. (1984). Phonological similarity and enhanced auditory recency in longer-term free recall. Quarterly Journal of Experimental Psychology, 36A, 13-27.

HarRis, R. L., Gausepohl, J., Lewis, R. J., Spoehr, K. T. (1979). The suffix effect: Postcategorical attributes in a serial recall paradigm. Bulletin of the Psychonomic Society, 13, 35-37.

HEDE, A. J. (1973). Stimulus array and recall method as variables in audio-visual split-span memory. Quarterly Journal of Experimental Psychology, 25, 130-137.

Hede, A. J. (1980). Dichotic and bisensory grouping effects. Quarterly Journal of Experimental Psychology, 32, 295-306.

НiтcH, G. J. (1974). Short-term memory for spatial and temporal information. Quarterly Journal of Experimental Psychology, 26, 503-513.

НІтсH, G. J. (1975). The role of attention in visual and auditory suffix effects. Memory \& Cognition, 3, 501-505.

HiтcH, G., \& MoRToN, J. (1975). The unimportance of explicit spatial information in serial recall of visually presented lists. Quarterly Journal of Experimental Psychology, 27, 161-164.

Hopkins, R. H., Edwards, R. E., \& Cook, C. L. (1973). Presentation modality, distractor modality, and proactive interference in shortterm memory. Journal of Experimental Psychology, 98, 362-367.

Huang, S.-T., Glenkerg, A. M. (1986). Echoic and retrieval accounts of the long-term modality effect tested using the suffix procedure. American Journal of Psychology, 99, 453-470. 
Johansson, B. S., \& NiLsson, L.-G. (1979). Boundary conditions for the modality effect: Type of material and time of test. Scandinavian Joumal of Psychology, 20, 26-35.

Kahneman, D. (1973). Attention and effort. Englewood Cliffs, NJ: Prentice-Hall.

Kahneman, D., \& HeniK, A. (1977). Effects of visual grouping on immediate recall and selective attention. In S. Dornic (Ed.), Attention and performance VI. Hillsdale, NJ: Erlbaum.

Kappel, S., Harford, M., Burns, V. D., \& Anderson, N. S. (1973). Effects of vocalization on short-term memory for words. Journal of Experimental Psychology, 101, 314-317.

Kellas, G., McCauley, C., \& McFarland, C. E., JR. (1975). ReeXamination of externalized rehearsal. Journal of Experimental Psychology: Human Learning \& Memory, 1, 84-90.

KirSner, K., \& DUNN, J. (1985). The perceptual record: A common factor in repetition priming and attribute retention. In $\mathbf{M}$. Posner \& $O$. Marin (Eds.), Attention and performance XI (pp. 547-565). Hillsdale, NJ: Erlbaum.

Kolers, P. A., Roediger, H. L. (1984). Procedures of mind. Journal of Verbal Learning \& Verbal Behavior, 23, 425-449.

Kroll, N. E. A. (1975). Visual short-term memory. In D. Deutsch \& S. A. Deutsch (Eds.), Short-term memory (pp. 153-179). New York: Academic Press.

Kroll, N. E. A., Parks, T., Parkinson, S. R., Bieber, S. L., \& JoHnson, A. L. (1970). Short-term memory while shadowing: Recall of visually and aurally presented letters. Journal of Experimental Psychology, 85, 220-224.

Laughery, K. R., \& Pinkus, A. L. (1966). Short-term memory: Effects of acoustic similarity, presentation rate and presentation mode. Psychonomic Science, 6, 285-286.

LEVY, B. A. (1971). Role of articulation in auditory and visual shortterm memory. Journal of Verbal Learning \& Verbal Behavior, 10 , 123-132.

MACKWORTH, J. F. (1962). The effect of display time upon the recall of digits. Canadian Joumal of Psychology, 16, 48-54.

MaCKWORTh, J. F. (1964). Auditory short-term memory. Canadian Journal of Psychology, 18, 292-303.

Madigan, S. A. (1971). Modality and recall order interactions in shortterm memory for serial order. Journal of Experimental Psychology, 87, 294-296.

Madsen, M. C., Rollins, H. A., \& Senf, G. M. (1970). Variables affecting immediate memory for bisensory stimuli: Eye-ear analogue studies of dichotic listening. Journal of Experimental Psychology Monographs, 83(3, Pt. 2)

ManNing, S. K. (1980). Tactual and visual alphanumeric suffix effects. Quarterly Journal of Experimental Psychology, 32, 257-267.

ManNing, S. K. (1987). Attentional control of visual suffix effects. Bulletin of the Psychonomic Society, 25, 423-426.

Manning, S. K., \& GMuer, B. A. (1985). Visual suffix effects on the Optacon: A test of changing state, primary linguistic, and attentional theories. Bulletin of the Psychonomic Society, 23, 1-4.

Manning, S. K., \& Pacifici, C. (1983). The effects of a suffix-prefix on forward and backward serial recall. American Journal of Psychology, 96, 127-134.

MANNING, S. K., \& TURNER, J. S. (1984). Recency and end-of-sequence suffix effects are not always linked. American Journal of Psychology, 97, 407-417.

MARCER, D. (1967). The effect of presentation method on short-term recall of CCC trigrams. Psychonomic Science, 8, 335-336.

MARCER, D. (1972). Interference and short-term retention. British Journal of Psychology, 63, 533-536.

MARGRAin, S. (1967). Short-term memory as a function of input modality. Quarterly Journal of Experimental Psychology, 19, 109-114.

MARTIN, M. (1980). Attention to words in different modalities: Fourchannel presentation with physical and semantic selection. Acta Psychologica, 44, 99-115.

Martin, M., \& Jones, G. V. (1979). Modality dependency of loss of recency in free recall. Psychological Research, 40, 273-289.

MAYES, J. T. (1988). On the nature of echoic persistence: Experiments with running memory. Journal of Experimental Psychology: Learning, Memory, \& Cognition, 14, 278-288.

MA YZNER, M. S., \& ADLER, S. (1965). A further study of information "chunking" and short-term retention. Journal of Psychology, 59, $125-130$.

MAYZner, M. S., \& GABRIEL, R. F. (1963). Information "chunking'" and short-term retention. Journal of Psychology, 56, 161-164.

MAYZNER, M. S., \& GABRIEL, R. F. (1964). The effect of spatial organization on short-term retention. Journal of Psychology, 58, 17-21.

MCFarland, C. E., JR., \& Kellas, G. (1974). Mode of input effects on subject-controlled processes. Joumal of Experimental Psychology, 103, 343-350.

McGhie, A., Chapman, J., \& Lawson, J. S. (1965). Changes in immediate memory with age. British Journal of Psychology, 59, 119-125.

MERIKLE, P. (1976). On the disruption of visual memory: Interference produced by visual report cues. Quarterly Journal of Experimental Psychology, 28, 193-202.

Metcalfe, J., Glavanov, D., \& Murdock, M. (1981). Spatial and temporal processing in the auditory and visual modalities. Memory \& Cognition, 9, 351-359.

MetCalfe, J., SharPe, D. (1985). Ordering and reordering in the auditory and visual modalities. Memory \& Cognition, 13, 435-441.

Morton, J. (1976). Two mechanisms in the stimulus suffix effect. Memory \& Cognition, 4, 144-149.

MowbraY, G. H. (1964). Perception and retention of verbal information presented during auditory shadowing. Journal of the Acoustical Society of America, 36, 1459-1464.

MURDOCK, B. B., JR. (1967). Auditory and visual stores in short-term memory. Acta Psychologica, 27, 316-324.

MURDOCK, B. B., JR. (1969). Where or when: Modality effects as a function of temporal and spatial distribution of information. Journal of Verbal Learning \& Verbal Behavior, 8, 378-383.

MURDOCK, B. B., JR. (1971). Four-channel effects in short-term memory. Psychonomic Science, 24, 197-198.

MURDOCK, B. B., JR., \& CAREY, S. T. (1972). Release from interference in single-trial free recall. Journal of Verbal Learning \& Verbal Behavior, 11, 398-402.

MURDOCK, B. B., JR., \& WALKER, K. D. (1969). Modality effects in free recall. Joumal of Verbal Leaming \& Verbal Behavior, 8, 665-676.

MURRAY, D. J. (1965). The effect of white noise upon the recall of vocalized lists. Canadian Journal of Psychology, 19, 333-345.

MURRAY, D. J. (1966). Vocalization at presentation and immediate recal with varying recall methods. Quarterly Joumal of Experimental Psychology, 18, 9-18.

MURRAY, D. J., \& RoBERTs, B. (1968). Visual and auditory presentation, presentation rate and short-term memory in children. British Journal of Psychology, 59, 119-125.

NaIrNe, J. S., CrowDer, R. G. (1982). On the locus of the stimulus suffix effect. Memory \& Cognition, 10, 350-357.

NAIRNE, J. S., \& PUSEN, C. (1984). Serial recall of imagined voices. Journal of Verbal Learning \& Verbal Behavior, 23, 331-342.

NAIRNE, J. S., \& WaLters, V. L. (1983). Silent mouthing produces modality-and suffix-like effects. Journal of Verbal Learning \& Verbal Behavior, 22, 475-483.

NiLsson, L.-G. (1973). Organization by modality in short-term memory. Journal of Experimental Psychology, 100, 246-253.

NILSSON, L.-G. (1974). Further evidence for organization by modality in immediate free recall. Journal of Experimental Psychology, 103, 948-957.

Nitsson, L.-G. (1979). A functional interpretation of the modality effect. Scandinavian Joumal of Psychology, 20, 259-265.

Nilsson, L.-G., Wright, E., \& MURDOCK, B. B., Jr. (1975). The effects of visual presentation method on single-trial free recall. Memory \& Cognition, 3, 427-433.

Nilsson, L.-G., Wright, E., Murdock, B. B., JR. (1979). Order of recall, output interference and the modality effect. Psychological Research, 41, 63-78.

Norman, D. A. (1969). Memory while shadowing. Quarterly Joumal of Experimental Psychology, 21, 85-93. 
O'Connor, N., \&ermelin, B. (1972). Seeing and hearing and space and time. Perception \& Psychophysics, 11, 46-48.

O'Connor, N., Hermelin, B. (1973). The spatial or temporal organization of short-term memory. Quarterly Joumal of Experimental Psychology, 25, 335-343

O'Connor, N., \& Hermelin, B. (1978). Seeing and hearing and space and time. London: Academic Press.

Parkinson, S. R. (1972). Short-term memory while shadowing: Multiple item recall of visually and aurally presented letters. Journal of Experimental Psychology, 92, 256-265.

Parkinson, S. R., Knight, M. V., Demaio, J. C., \& Connors, J. F. (1974). Channels and order of report in dichotic memory. Perception \& Psychophysics, 16, 235-241.

Parkinson, S. R., Parks, T. E., \& Kroll, N. E. A. (1971). Visual and auditory short-term memory: Effects of phonemically similar auditory shadow material during the retention interval. Joumal of Experimental Psychology, 87, 274-280.

Peca, T. A., Reid, H. M., \& Mason, S. W. (1982). Effect of input modality and orienting task on memory. Perceptual \& Motor Skills, $55,1216$.

PenNeY, C. G. (1973). Bisensory studies in short-term memory: New light on the effects of presentation modality. Unpublished doctoral dissertation, University of Toronto.

PenNey, C. G. (1974a). Dichotic listening and sequential associations in auditory short-term memory. Joumal of Experimental Psychology, $102,142-150$.

PenNey, C. G. (1974b). Order of report and interference effects in fourchannel bisensory memory. Canadian Journal of Psychology, 28. 371-382.

PenNey, C. G. (1975). Modality effects in short-term verbal memory. Psychological Bulletin, 82, 68-84.

PenNey, C. G. (1976). Order information in dichotic memory. Journal of Experimental Psychology: Human Learning \& Memory, 2 , 340-346.

Penney, C. G. (1978). Suffix effects in lists of temporally grouped words. Quarterly Journal of Experimental Psychology, 30, 235-250.

PenNEY, C. G. (1979). Interactions of suffix effects with suffix delay and recall modality in serial recall. Journal of Experimental Psychology, 5, 507-521.

PenNey, C. G. (1980). Order of report in bisensory verbal short-term memory. Canadian Journal of Psychology, 34, 190-195.

PENNEY, C. G. (1982a). Serial recall versus recall by categories in shortterm memory. Canadian Journal of Psychology, 36, 83-93.

PenNey, C. G. (1982b). Suffix effects and probe modality in probed recall: Implications for readout from sensory memory. Quarterly Journal of Experimental Psychology, 34A, 245-257.

PenNey, C. G. (1985). Elimination of the suffix effect on preterminal list items with unpredictable list length: Evidence for a dual model of suffix effects. Journal of Experimental Psychology: Learning, Memory, \& Cognition, 11, 229-247.

PENNEY, C. G. (1986, November). The effects of orienting task and presentation modality upon judged frequency. Paper presented at the annual meeting of the Psychonomic Society, New Orleans.

Penney, C. G., \& Butr, A. K. (1986). Within- and between-modality associations in probed recall: A test of the separate-streams hypothesis. Canadian Joumal of Psychology, 40, 1-11.

Peterson, L. R., \& Johnson, S. T. (1971). Some effects of minimizing articulation on short-term retention. Joumal of Verbal Learning \& Verbal Behavior, 10, 346-354.

Proctor, R. W., \& Fagnani, C. A. (1978). Effects of distractorstimulus modality in the Brown-Peterson distractor task. Journal of Experimental Psychology: Human Learning \& Memory, 4, 676-684.

RoBERTs, L. A. (1986). Modality and suffix effects in memory for melodic and harmonic musical materials. Cognitive Psychology, 18, 123-157.

RoBerTs, W. A. (1972). Free recall of word lists varying in length and rate of presentation: A test of total time hypotheses. Journal of $E x$ perimental Psychology, 92, 365-372.
Roluins, H. A. (1972). Serial position effects in simultaneous bisensory memory. Journal of Experimental Psychology, 94, 162-167.

Rollins, H. A., JR., \& Hendricks, R. (1980). Processing of words presented simultaneously to eye and ear. Joumal of Experimental Psychology: Human Perception \& Performance, 6, 99-109.

Rollins, H. A., Schurman, D. L., Evans, M. J., K KNOPh, K (1975). Auditory versus visual processing of three sets of simultaneous digits pairs. Journal of Experimental Psychology: Human Learning \& Memory, 1, 173-181.

Rollins, H. A., \& Thibadeau, R. (1973). The effects of auditory shadowing on recognition of information received visually. Memory \& Cognition, 1, 164-168.

RönnberG, J., Nilsson, L.-G., \& OHLSSON, K. (1982). Organization by modality, language, and category compared. Psychological Research, 44, 369-379.

RönnberG, J., \& OHLsson, K. (1980). Channel capacity and processing of modality specific information. Acta Psychologica, 44, 253-267.

RouTh, D. A. (1970). 'Trace strength,' modality, and the serial position curve in immediate memory. Psychonomic Science, 18, 355-357.

Routh, D. A. (1976). An 'across-the-board' modality effect in immediate serial recall. Quarterly Journal of Experimental Psychology, 28, 285-304

Routr, D. A., \& Lifschutz, A. J. (1975). An asymmetrical effect of similarity in the attenuation of stimulus suffix interference. Journal of Verbal Learning \& Verbal Behavior, 14, 95-104.

RowE, E. J., \& RowE, W. G. (1976). Stimulus suffix effects with speech and nonspeech sounds. Memory \& Cognition, 4, 128-131.

RyaN, J. (1969a). Grouping and short-term memory: Different means and patterns of grouping. Quarterly Joumal of Experimental Psychology, 21, 137-147

RYAN, J. (1969b). Temporal grouping, rehearsal and short-term memory. Quarterly Journal of Experimental Psychology, 21, 148-155.

Saffran, E. M., MARIN, O. S. M. (1975). Immediate memory for word lists and sentences in a patient with deficient auditory short-term memory. Brain \& Language, 2, 420-433.

Salamé, P., \& Baddeley, A. D. (1982). Disruption of short-term memory by unattended speech: Implications for the structure of working memory. Journal of Verbal Learning \& Verbal Behavior, 21, $150-164$

Salter, D., \& Colley, J. G. (1977). The stimulus suffix: A paradoxical effect. Memory \& Cognition, 5, 257-262.

Salzberg, P. M., Parks, T. E., Kroll, N. E. A., \&arkinson, S. R. (1971). Retroactive effects of phonemic similarity on short-term recall of visual and auditory stimuli. Journal of Experimental Psychology, 91, 43-46

SAmpSON, H., \& SPong, P. (1961). Handedness, eye-dominance, and immediate memory. Quarterly Journal of Experimental Psychology, 13, 173-180.

SAvin, H. B. (1967). On the successive perception of simultaneous stimuli. Perception \& Psychophysics, 2, 479-482.

Schurman, D., Everson, M. D., \& Rollins, H. A. (1972). Successive vs simultaneous processing of superimposed visual stimuli. Perception \& Psychophysics, 11, 420-422.

SENF, G. M., \& RoluINS, H. A. (1971). Effect of precuing versus postcuing retrieval order on the accuracy of bisensory memory. Journal of Experimental Psychology, 88, 12-15.

Shaffer, L. H. (1975). Multiple attention in continuous verbal tasks. In P. M. A. Rabbitt \& S. Dornic (Eds.), Attention and performance $V$ (pp.157-167). London: Academic Press.

Shallice, T., \& Warrington, E. K. (1970). Independent functioning of verbal memory stores: A neuropsychological study. Quarterly Journal of Experimental Psychology, 22, 261-273.

Shallice, T., \& Warrington, E. K. (1977). Auditory-verbal shortterm memory impairment and condition aphasia. Brain \& Language, 4, 480-491.

Shand, M. A., \& Klima, E. S. (1981). Nonauditory suffix effects in congenitally deaf signers of American Sign Language. Joumal of Experimental Psychology: Human Learning \& Memory, 7, 464-474. 
Snodgrass, J. G., \& ANTone, G. (1974). Parallel versus sequential processing of pictures and words. Joumal of Experimental Psychology, 103, 129-144.

SPERLING, G. (1963). A model for visual memory tasks. Human Factors, 5, 19-31.

SPERLING, G. (1967). Successive approximations to a model for shortterm memory. Acta Psychologica, 27, 285-292.

Spoenr, K. T., \& Corin, W. J. (1978). The stimulus suffix effect as a memory coding phenomenon. Memory \& Cognition, 6, 583-589.

Strub, R. L., \& GARDINER, H. (1974). The repetition defect in conduction aphasia: Mnestic or linguistic? Brain \& Language, 1, 241-255.

$T_{\text {AUB }}, \mathrm{H}$. A. (1972). A comparison of young adult and old groups on various digit span tasks. Developmental Psychology, 6, 60-65.

Tell, P. M., \& Ferguson, A. M. (1974). Influence of active and passive vocalization on short-term recall. Journal of Experimental Psychology, 102, 347-349.

Treisman, A. M. (1960). Contextual cues in selective listening. Quarterly Journal of Experimental Psychology, 12, 242-248.

Treisman, A. M. (1964). Monitoring and storage of irrelevant messages in selective attention. Journal of Verbal Learning \& Verbal Behavior, 3, 449-459.

Treisman, A. M., \& Davies, A. (1973). Divided attention to ear and eye. In S. Kornblum (Ed.), Attention and performance IV (pp. 101117). New York: Academic Press.

Turner, M. L., LaPointe, L. B., Cantor, J., Reeves, C. H., Griffith, R. H., \& ENGLE, R. W. (1987). Recency and suffix effects found with auditory presentation and mouthed visual presentation: They're not the same thing. Journal of Memory \& Language, 26, 138-164.

Tzortzis, C., \& ALBert, M. L. (1974). Impairment of memory for sequences in conduction aphasia. Neuropsychologia, 12, 355-366.

VAllar, G., \& BadDeley, A. D. (1984). Fractionation of working memory: Neuropsychological evidence for a phonological short-term store. Journal of Verbal Learning \& Verbal Behavior, 23, 151-161.

Warrington, E. K., Logue, V., \& Pratt, R. T. C. (1971). The anatomical localization of selective impairment of auditory-verbal shortterm memory. Neuropsychologia, 9, 377-388.

Warrington, E. K., \& RABIN, P. (1971). Visual span of apprehen- sion in patients with unilateral cerebral lesions. Quarterly Journal of Experimental Psychology, 23, 423-431.

Warrington, E. K., \& Shallice, T. (1969). The selective impairment of auditory verbal short-term memory. Brain, 92, 885-896.

WarRINGTON, E. K., \& SHAllice, T. (1972). Neuropsychological evidence of visual storage in short-term memory tasks. Quarterly Journal of Experimental Psychology, 24, 34-40.

WATKINS, M. J. (1972). Locus of the modality effect in free recall. Journal of Verbal Learning \& Verbal Behavior, 11, 644-648.

Watkins, M. J., \& PeYnircioglu, Z. F. (1983). Interaction between presentation modality and recall order in memory span. American Journal of Psychology, 96, 315-322.

W ATkINS, M. J., \& Todres, A. K. (1980). Suffix effects manifest and concealed: Further evidence for a 20 -second echo. Journal of Verbal Learning \& Verbal Behavior, 19, 46-53.

WatkIns, M. J., \& WatKINS, O. C. (1973). The post-categorical status of the modality effect in serial recall. Joumal of Experimental Psychology, 99, 226-230.

Watkins, M. J., \& Watkins, O. C. (1974). A tactile suffix effect. Memory \& Cognition, 2, 176-180.

Watkins, O. C., \& WatkINS, M. J. (1980). The modality effect and echoic persistence. Journal of Experimental Psychology: General, 109, 251-278.

Watkins, O. C., \& WatKINS, M. J. (1982). Lateral inhibition and echoic memory: Some comments on Crowder's (1978) theory. Memory \& Cognition, 10, 279-286.

Watkins, M. J., Watkins, O. C., \& Crowder, R. G. (1974). The modality effect in free and serial recall as a function of phonological similarity. Journal of Verbal Learning \& Verbal Behavior, 13, 430-447.

Whitmore, M. G. (1972). Stimulus meaning as a variable in dichotic listening. Psychonomic Science, 26, 207-208.

YNTEMA, D. B., \& TRASK, F. P. (1963). Recall as a search process. Journal of Verbal Learning \& Verbal Behavior, 2, 65-74.

(Manuscript received September 4, 1987; revision accepted for publication October 24,1988 .) 